\title{
Numerical Simulations for Nonlinear Waves Interaction with Multiple Perforated Quasi-Ellipse Caissons
}

\author{
Xiaozhong $\operatorname{Ren}^{1}$ and Yuxiang $\mathrm{Ma}^{2}$ \\ ${ }^{1}$ Dalian Jiucheng Municipal Design Co. Ltd., Dalian 116000, China \\ ${ }^{2}$ State Key Laboratory of Coastal and Offshore Engineering, Dalian University of Technology, Dalian 116024, China \\ Correspondence should be addressed to Yuxiang Ma; yuxma@dlut.edu.cn
}

Received 9 April 2015; Revised 15 June 2015; Accepted 16 June 2015

Academic Editor: Ming Zhao

Copyright (c) $2015 \mathrm{X}$. Ren and Y. Ma. This is an open access article distributed under the Creative Commons Attribution License, which permits unrestricted use, distribution, and reproduction in any medium, provided the original work is properly cited.

\begin{abstract}
A three-dimensional numerical flume is developed to study cnoidal wave interaction with multiple arranged perforated quasiellipse caissons. The continuity equation and the Navier-Stokes equations are used as the governing equation, and the VOF method is adopted to capture the free surface elevation. The equations are discretized on staggered cells and then solved using a finite difference method. The generation and propagation of cnoidal waves in the numerical flume are tested first. And the ability of the present model to simulate interactions between waves and structures is verified by known experimental results. Then cnoidal waves with varying incident wave height and period are generated and interact with multiple quasi-ellipse caissons with and without perforation. It is found that the perforation plays an effective role in reducing wave runup/rundown and wave forces on the caissons. The wave forces on caissons reduce with the decreasing incident wave period. The influence of the transverse distance of multiple caissons on wave forces is also investigated. A closer transverse distance between caissons can produce larger wave forces. But when relative adjacent distance $L / D$ ( $L$ is the transverse distance and $D$ is the width of the quasi-ellipse caisson) is larger than 3 , the effect of adjacent distance is limited.
\end{abstract}

\section{Introduction}

Perforated caissons, which can not only weaken the wave reflection but also reduce the wave forces [1], are now common protection structures in coastal engineering, especially in the construction of vertical breakwaters and wharfs.

During the past decades, many studies were carried out to investigate the performances of perforated structures, but mainly on perforated circular and rectangular caissons. Huang et al. [2] presented a comprehensive review on the hydraulic performance and wave loadings of perforated/slotted coastal structures. Using the eigenfunction expansion method, Darwiche et al. [3] theoretically investigated the interaction of linear waves with a cylindrical breakwater surrounding a semiporous circular cylinder and found that the semiporous structure can significantly reduce wave load. Yip and Chwang [4] proposed a perforated wall breakwater with an internal horizontal plate and studied the hydrodynamic performance of this type of structure theoretically. Suh et al. [5] developed an analytical model to predict irregular wave reflection of a perforated wall caisson and the ability of the model was tested by an experiment. Li et al. [6] presented analytical results on the reflection of obliquely incident waves by breakwaters with a partially perforated wall and then further examined the wave absorbing performance of the breakwater with double partially perforated front walls [7]. Later, Liu et al. [8] developed a theoretical model to study the hydrodynamic performance of a perforated wall breakwater with a submerged horizontal porous plate using the linear potential theory. Using the same method, the reflection of obliquely incident waves by an infinite array of partially perforated caisson was also investigated [9]. Using the eigenfunction expansion method, Sankarbabu et al. [10] theoretically examined the hydrodynamic performance of a dual cylindrical breakwater which was formed by a row of caissons each of which consists of a porous outer cylinder circumscribing an impermeable inner cylinder.

Neelamani et al. [11] conducted an experiment on wave interaction with a vertical cylinder encircled by a perforated square caisson and found that the wave forces and 
moments on the cylinder are influenced by the porosity of the outer caisson. Vijayalakshmi et al. [12] experimentally studied wave runup and rundown on a twin perforated circular cylinder and then developed a predictive formula for the wave runup and rundown on the perforated cylinder based on the experimental results. Liu et al. [13] performed an experimental and theoretical study on wave forces on partially perforated rectangular caissons by normally incident irregular waves. Lee and Shin [14] experimentally tested wave reflection of partially perforated wall caisson structures with single and double chambers. Lee et al. [15] conducted a three-dimensional experiment to study the evolution of stem waves on partially perforated walls and found that the perforation can effectively reduce wave height.

As aspects on numerical simulations, Chen et al. [16] developed a numerical model based on a two-dimensional VOF method combined with the $k-\varepsilon$ model and used the model to study wave interactions with perforated rectangular caisson breakwaters. Later, this model was extended to investigate wave forces on a perforated caisson with a top cover. Liu et al. [17] used the semianalytical scaled boundary finite element method to deal with the short-crested wave interaction with a concentric cylindrical structure with doublelayered perforated walls. Later, Liu and Lin [18] extended the numerical model to study short-crested wave interaction with a concentric cylindrical system. Recently, Aristodemo et al. [19] developed a numerical model based on the SPH method to calculate wave pressures acting on vertical and slotted coastal structures.

The type of quasi-ellipse caisson is a relatively new structure. For open deep-water wharves, quasi-ellipse caissons were proven to be more effective and economical than the circular and rectangular caissons [20]. It was used to support gravity dolphin wharves in Dalian Ore Terminal Phase II Project, Dalian, China, and the ore wharf of Dongjiakou Port, Tsingtao, China. Compared with the researches on the circular and rectangular types, investigations on the hydrodynamics of quasi-ellipse caissons are rare, especially for the perforated ones. Wang et al. [21] developed a 3D numerical model based on the VOF method to study the interactions between waves and a single quasi-ellipse caisson. It was found that both wave height and caisson size have significant influences on the wave forces on the caisson. However, in real project, caissons are always arranged in groups. Therefore, the efforts on the interactions between waves and multiple quasi-ellipse caissons with and without perforation should be carried out. This is the main aim of the present study. In this study, the numerical model developed by Wang et al. [21] is extended to study normally incident cnoidal waves interaction with multiple quasi-ellipse caissons and the influence of perforation.

Following the introduction, the detailed setup of a 3D numerical model is described in Section 2. Then, the model is validated in Section 3. Simulations on interactions between waves and multiple caissons with and without perforation and the results are under discussion in Section 4. Lastly, some conclusions are advanced in Section 5.

\section{Numerical Model}

In this section, the governing equations and numerical algorithm are introduced in detail, especially for the treatment of the boundary conditions. Figure 1 shows the schematic drawing of the present model, where $L$ is the tank length, $B$ is the tank width, $d$ is the still water depth, $L_{1}$ is the length of the working zone of the tank, and $L_{2}$ is the length of the sponger layer. The origin of the Cartesian coordinate system oxyz is set in the corner of the bottom with the $x$-axis positive in the direction of incoming wave propagation and the $z$-axis positive upwards as shown in Figure 1.

2.1. Government Equations. In this study, the flow is assumed to be incompressible. The continuity equation and the NavierStokes equations are adopted as the governing equations. And the water surface is traced by the volume of fluid (VOF) method.

Continuity equation is as follows:

$$
\frac{\partial}{\partial x}(\theta u)+\frac{\partial}{\partial y}(\theta v)+\frac{\partial}{\partial z}(\theta w)=0 .
$$

Navier-Stokes equations are as follows:

$$
\begin{aligned}
\frac{\partial u}{\partial t} & +u \frac{\partial u}{\partial x}+v \frac{\partial u}{\partial y}+w \frac{\partial u}{\partial z} \\
& =-\frac{1}{\rho} \frac{\partial p}{\partial x}+v_{k}\left(\frac{\partial^{2} u}{\partial x^{2}}+\frac{\partial^{2} u}{\partial y^{2}}+\frac{\partial^{2} u}{\partial z^{2}}\right), \\
\frac{\partial v}{\partial t} & +u \frac{\partial v}{\partial x}+v \frac{\partial v}{\partial y}+w \frac{\partial v}{\partial z} \\
& =-\frac{1}{\rho} \frac{\partial p}{\partial y}+g+v_{k}\left(\frac{\partial^{2} v}{\partial x^{2}}+\frac{\partial^{2} v}{\partial y^{2}}+\frac{\partial^{2} v}{\partial z^{2}}\right), \\
\frac{\partial w}{\partial t} & +u \frac{\partial w}{\partial x}+v \frac{\partial w}{\partial y}+w \frac{\partial w}{\partial z} \\
& =-\frac{1}{\rho} \frac{\partial p}{\partial z}+v_{k}\left(\frac{\partial^{2} w}{\partial x^{2}}+\frac{\partial^{2} w}{\partial y^{2}}+\frac{\partial^{2} w}{\partial z^{2}}\right),
\end{aligned}
$$

where $u, v$, and $w$ are the velocity components in the $x$, $y$, and $z$ directions, respectively, $t$ represents the time, $g$ is the gravitational acceleration, $\rho$ is the fluid density and is equal to $1000 \mathrm{~kg} / \mathrm{m}^{3}, p$ is the pressure, $v_{k}$ is the coefficient of kinematic viscosity and is set to $1.0 \times 10^{-6} \mathrm{~m}^{2} / \mathrm{s}, \theta$ is the volume fraction of the partial cell, and its value is determined after the computational discretization.

To capture the free surfaces, a function $F(x, y, x, t)$ is introduced. The value of $F$ in a cell represents the occupation ratio by fluid; $F=1$ for a cell full with fluid, whereas $F=0$ for a cell without fluid. Cells with $F$ values between 0 and 1 indicate that the cells are partially filled with fluid. These cells are intersected by the free surface or contain bubbles which are smaller than the cells $[22,23]$. The time dependence of $F$ can be handled by

$$
\frac{\partial}{\partial t}(\theta F)+\frac{\partial}{\partial x}(\theta u F)+\frac{\partial}{\partial y}(\theta v F)+\frac{\partial}{\partial z}(\theta w F)=0 .
$$




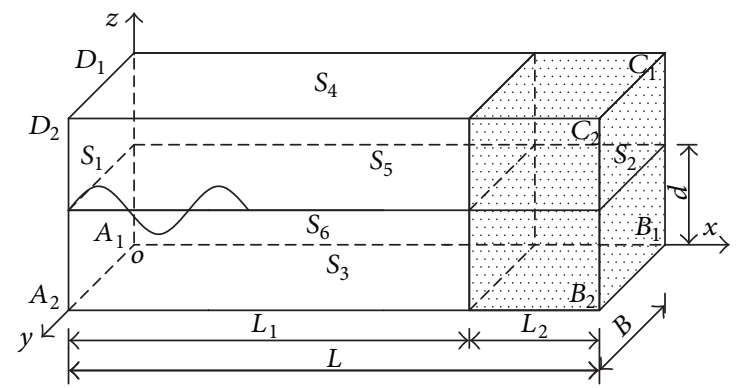

FIGURE 1: Schematic drawing of the numerical tank and the coordinate system.

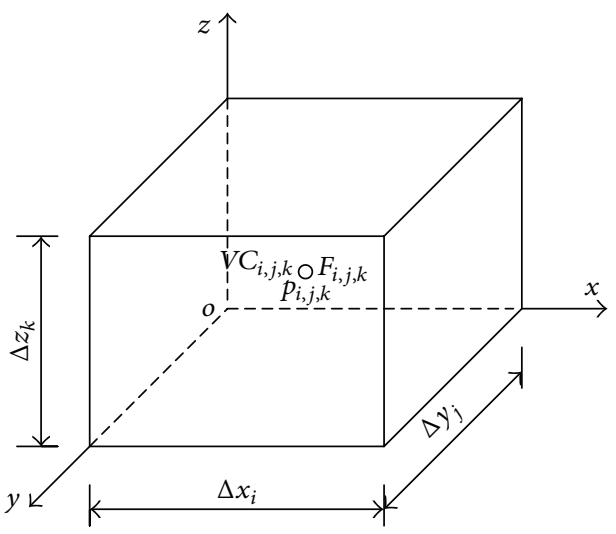

(a)

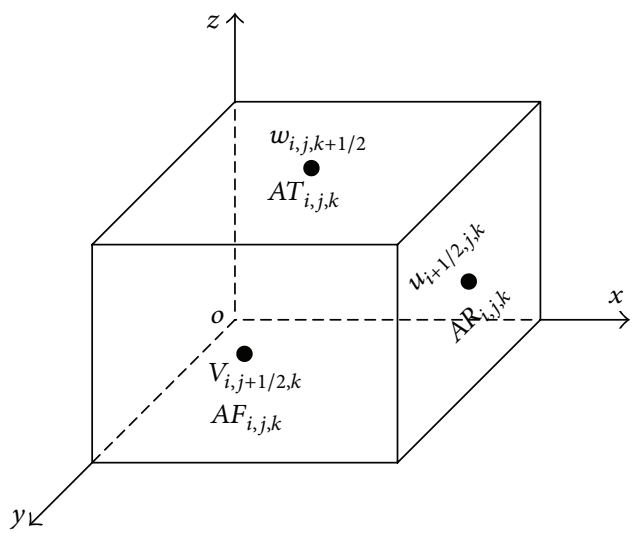

(b)

Figure 2: Parameter definition of staggered cells: (a) at the center of a cell, (b) at the sides of a cell.

2.2. Discretization Scheme. A finite difference method is chosen to solve the governing equations. The staggered cell is adopted for the computational discretization. The locations of the variations, $p, F, u, v$, and $w$, used in the computation are illustrated in Figure 2. Quantities, $A R_{i, j, k}, A T_{i, j, k}, A F_{i, j, k}$, and $V C_{i, j, k}$, denote the fractions open to flow for the right, top, and front cell faces and the cell volume, respectively.

The discretization scheme of the continuity equation is written as

$$
\begin{gathered}
\frac{1}{V C_{i, j, k}}\left(\frac{u_{i, j, k}^{n+1} A R_{i, j, k}-u_{i-1, j, k}^{n+1} A R_{i-1, j, k}}{\Delta x_{i}}\right. \\
+\frac{v_{i, j, k}^{n+1} A F_{i, j, k}-v_{i, j-1, k}^{n+1} A F_{i, j-1, k}}{\Delta z_{k}} \\
\left.+\frac{w_{i, j, k}^{n+1} A T_{i, j, k}-w_{i, j, k-1}^{n+1} A T_{i, j, k-1}}{\Delta y_{j}}\right)=0 .
\end{gathered}
$$

The time derivative is discretized by the forward time difference scheme for the momentum equations; the finite difference approximation for a typical cell in $x$ direction is given as follows:

$$
\begin{aligned}
& u_{i, j, k}^{n+1}=u_{i, j, k}^{n}+\frac{\Delta t}{\Delta x}\left[-\left(p_{i+1, j, k}^{n+1}-p_{i, j, k}^{n+1}\right)-\mathrm{FUX}-\mathrm{FUY}\right. \\
& -\mathrm{FUZ}+\mathrm{VISX}]
\end{aligned}
$$

where FUX, FUY, and FUZ are the convection flux terms in the three directions and a combination of the central difference scheme and the upwind scheme is employed to discretize them. For example, the discretized form for FUX is defined as

$$
\begin{aligned}
& \text { FUX }=\left(u \frac{\partial u}{\partial x}\right)_{i+1, j, k}=\frac{u_{i, j, k}^{n}}{\Delta x_{\alpha}}\left\{\frac{\Delta x_{i+1}}{\Delta x_{i}}\left(u_{i, j, k}^{n}-u_{i-1, j, k}^{n}\right)\right. \\
& +\frac{\Delta x_{i}}{\Delta x_{i+1}}\left(u_{i+1, j, k}^{n}-u_{i, j, k}^{n}\right)+\alpha \cdot \operatorname{sign}\left(u_{i, j, k}^{n}\right) \\
& \quad \cdot\left[\frac{\Delta x_{i+1}}{\Delta x_{i}}\left(u_{i, j, k}^{n}-u_{i-1, j, k}^{n}\right)\right. \\
& \left.\left.+\frac{\Delta x_{i}}{\Delta x_{i+1}}\left(u_{i+1, j, k}^{n}-u_{i, j, k}^{n}\right)\right]\right\}, \\
& \Delta x_{\alpha}=\Delta x_{i+1}+\Delta x_{i}+\alpha \cdot \operatorname{sign}\left(u_{i, j, k}^{n}\right)\left(\Delta x_{i+1}-\Delta x_{i}\right), \\
& \operatorname{sign}(u)=\left\{\begin{array}{cc}
1 & u>0 \\
-1 & u<0,
\end{array}\right.
\end{aligned}
$$

where $\alpha$ is a parameter to control the difference scheme, $\alpha=0$ indicates the central difference scheme is used, and $\alpha=1$ denotes the first-order upwind scheme is invoked. In this 
study, $\alpha=0.5$ is used. For the viscosity term VISX, the second-order central difference scheme is applied:

$$
\begin{aligned}
& \mathrm{VISX}=\left[v_{k}\left(\frac{\partial^{2} u}{\partial x^{2}}+\frac{\partial^{2} u}{\partial y^{2}}+\frac{\partial^{2} u}{\partial z^{2}}\right)\right]_{i+1, j, k} \\
& =\frac{v_{k}}{\Delta x_{i+1 / 2} \Delta x_{i+1} \Delta x_{i}}\left[\Delta x_{i}\left(u_{i+1, j, k}^{n}-u_{i, j, k}^{n}\right)\right. \\
& \left.-\Delta x_{i+1}\left(u_{i, j, k}^{n}-u_{i-1, j, k}^{n}\right)\right] \\
& +\frac{v_{k}}{\left(\Delta y_{j+1 / 2}+\Delta y_{j-1 / 2}\right) \Delta y_{j+1 / 2} \Delta y_{j-1 / 2}}\left[\Delta y _ { j - 1 / 2 } \left(u_{i, j+1, k}^{n}\right.\right. \\
& \left.\left.-u_{i, j, k}^{n}\right)-\Delta y_{j+1 / 2}\left(u_{i, j, k}^{n}-u_{i, j-1, k}^{n}\right)\right] \\
& +\frac{v_{k}}{\left(\Delta z_{k+1 / 2}+\Delta z_{k-1 / 2}\right) \Delta z_{k+1 / 2} \Delta z_{k-1 / 2}}\left[\Delta z _ { k - 1 / 2 } \left(u_{i, j, k+1}^{n}\right.\right. \\
& \left.\left.-u_{i, j, k}^{n}\right)-\Delta z_{k+1 / 2}\left(u_{i, j, k}^{n}-u_{i, j, k-1}^{n}\right)\right] .
\end{aligned}
$$

Additionally, the convection flux and viscosity terms in the other two directions can be obtained in the same way.

\subsection{Velocity-Pressure Coupling and Free Surface Capturing} At each time step, the velocity field and pressure in each control volume must be solved. For each cell, the velocities at the time step $t_{n+1}$ are approximately obtained from the momentum equations using the values at $t_{n}$. Then, the pressure and velocities must be iterated until the continuity equation is satisfied to the required accuracy. In this study, the iteration accuracy is set to $\varepsilon<0.005$.

For the cells which are fully occupied by fluid, the velocity-pressure coupling is completed in the following process. Let $S_{n+1}$ represent the left term of the continuous equation at the time step $t_{n+1}$. The continuity equation is satisfied when $S_{n+1}$ approaches zero. This process is completed by changing the pressure and can be defined as

$$
\delta p=-\frac{S_{n+1}^{m}}{\partial S_{n+1}^{m} / \partial p}
$$

where the subscript $m$ represents the $m$ th iteration and the term $\partial S_{n+1}^{m} / \partial p$ can be defined as

$$
\begin{aligned}
\frac{\partial S}{\partial p} & =\frac{\Delta t}{V C_{i, j, k}}\left\{\frac { 1 } { \Delta x _ { i } } \left(\frac{1}{\Delta x_{i+1 / 2}} A R_{i, j, k}\right.\right. \\
& \left.+\frac{1}{\Delta x_{i-1 / 2}} A R_{i-1, j, k}\right)+\frac{1}{\Delta y_{j}}\left(\frac{1}{\Delta y_{j+1 / 2}} A F_{i, j, k}\right. \\
& \left.+\frac{1}{\Delta y_{j-1 / 2}} A F_{i, j-1, k}\right)+\frac{1}{\Delta z_{k}}\left(\frac{1}{\Delta z_{k+1 / 2}} A T_{i, j, k}\right. \\
& \left.\left.+\frac{1}{\Delta z_{k-1 / 2}} A T_{i, j, k-1}\right)\right\} .
\end{aligned}
$$

For the cells containing a free surface, the free surface boundary condition is satisfied by setting the surface cell pressure $p_{i, j, k}^{n}$ equal to the value obtained by a linear interpolation between the surface pressure $p_{s}$ and the pressure of the corresponding cell fully occupied by fluid below the surface cell, $p_{n}$ :

$$
\delta p=\left(1-\frac{d_{c}}{d_{f}}\right) p_{n}+\frac{d_{c}}{d_{f}} p_{s}-p_{i, j, k}^{n},
$$

where $d_{c}$ is the distance between the two interpolation cells and $d_{f}$ is the distance from the below cell to the free surface.

After the velocity field and pressure have been obtained by the above iteration process in each computational cell occupied by fluid, the volume of fluid function $F$ is then computed for the new time level to give the new fluid configuration. The fact that $F$ is a step function requires special care in computing the fluxes to preserve the sharp definition of a free surface; here a donor-acceptor flux approximation of the SOLA-VOF method $[22,23]$ is used to determine the $F$ function at each interface.

2.4. Boundary Conditions. As shown in Figure 1, the wave maker is set on the left side of the numerical tank $\left(S_{1}\right)$. To generate nonlinear shallow waves and mitigate re-reflected waves at the wave maker, the numerical absorbing cnoidal wave maker proposed by Wang et al. [24] is adopted. Namely, the paddle velocity is defined:

$$
\begin{aligned}
U\left(k^{\prime}, t+1\right)= & \frac{\eta_{0}\left(k^{\prime}, t\right) c}{d+\eta_{0}\left(k^{\prime}, t\right)} \\
& +\frac{\left[\eta_{0}\left(k^{\prime}, t\right)-\eta\left(k^{\prime}, t\right)\right] c}{d+\eta_{0}\left(k^{\prime}, t\right)-\eta\left(k^{\prime}, t\right)},
\end{aligned}
$$

where $\eta\left(k^{\prime}, t\right)$ is the actual wave elevation at the $k^{\prime}$ th cell of the wave maker, $\eta_{0}\left(k^{\prime}, t\right)$ is the theoretical wave elevation, and $c$ is the celerity of the cnoidal wave.

A sponge layer (as shown in Figure 1) is set to absorb the outgoing waves, and the reduction coefficient of particle velocities is defined as

$$
\mu(x)= \begin{cases}\sqrt{1-\left(\frac{x-L_{1}}{L_{2}}\right)}, & L_{1} \leq x \leq L, \\ 1, & x<L_{1} .\end{cases}
$$

Besides the sponge layer, the Sommerfeld radiation condition is adopted at the right boundary of the flume. Additionally, sidewall boundaries $\left(S_{5}, S_{6}\right)$ and the bottom boundary $\left(S_{3}\right)$ of the numerical tank are treated as freeslip rigid walls; that is, the normal velocities at the freeslip boundaries and the normal derivative of the tangential velocities are both set to zero.

\section{Validation of the Model}

Before using the present model to study the interaction of waves and quasi-ellipse caissons, its performance for simulating waves and their interaction with structures should be validated. In this section, the ability of the numerical model is verified using theoretical and existing experimental results. 


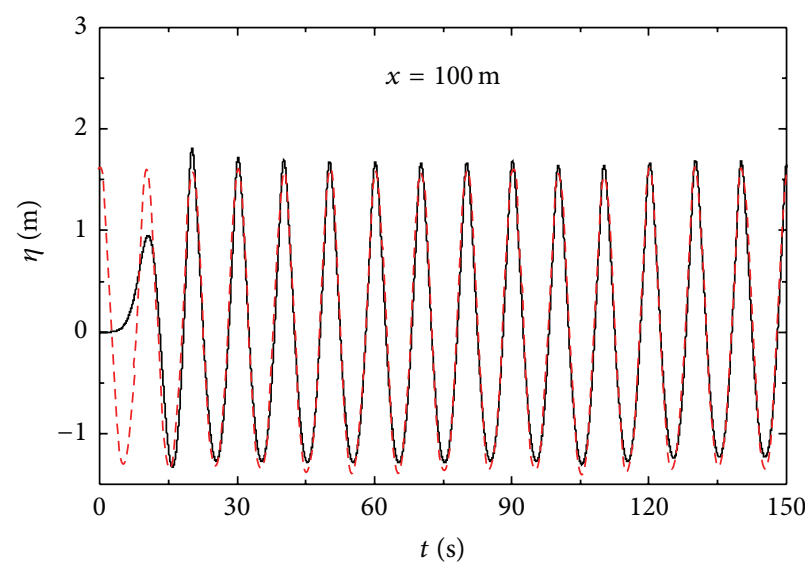

(a)

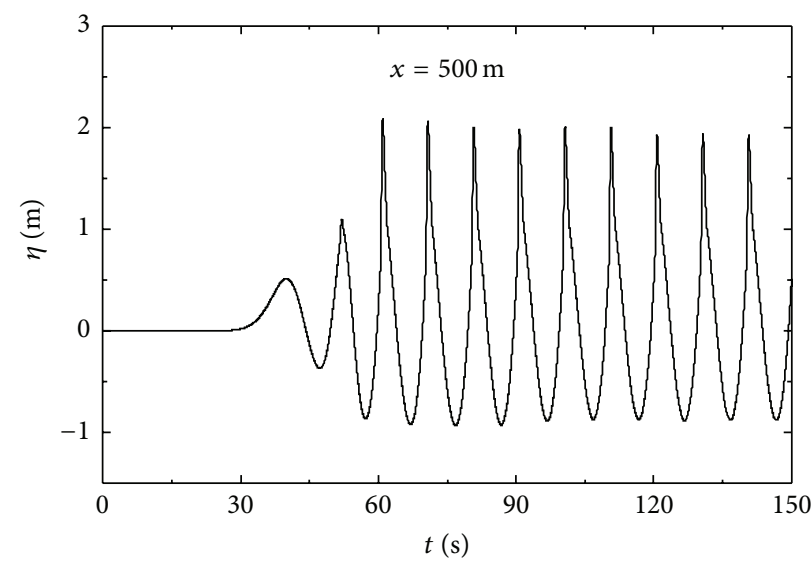

(c)

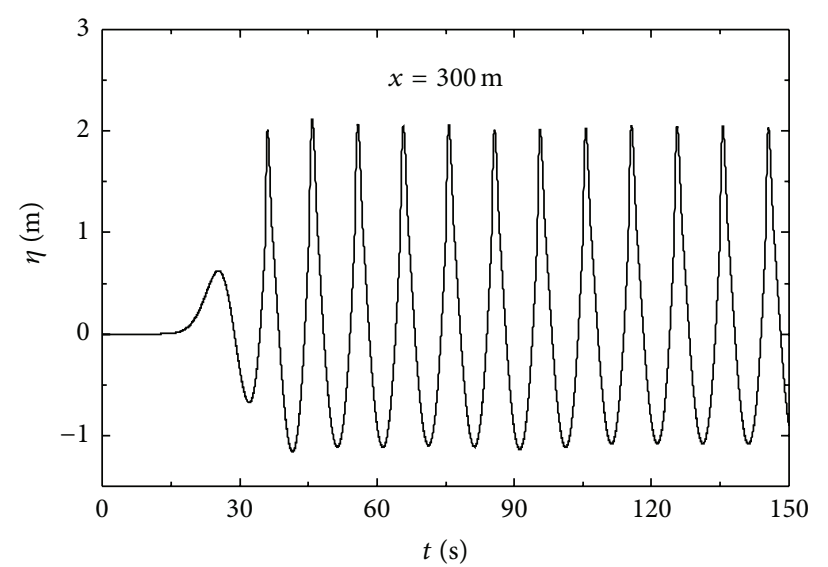

(b)

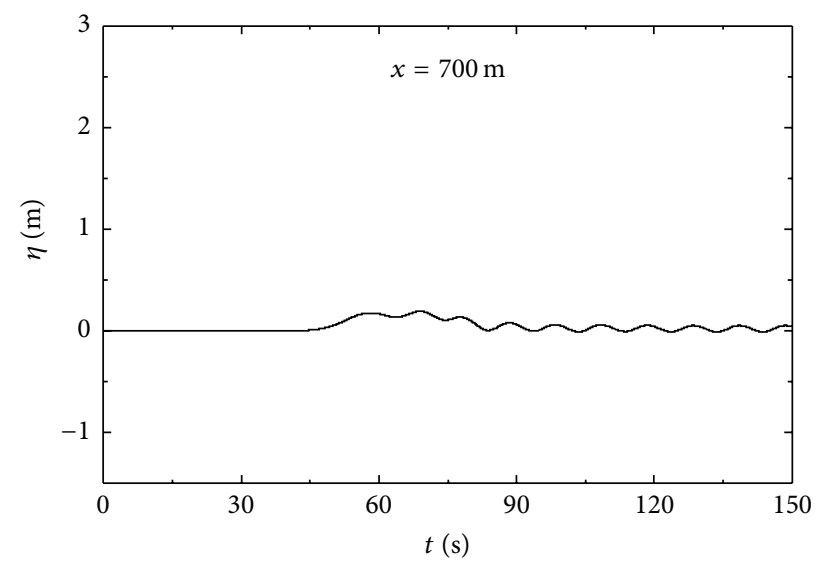

(d)

Figure 3: The simulated wave surface elevations at different locations along the tank for a case with $H=3 \mathrm{~m}, T=10 \mathrm{~s}$ (the red dash line in the panel of $x=100 \mathrm{~m}$ is the corresponding theoretical solution).

3.1. Wave Generation and Propagation. Tests of the wave generation of the numerical wave tank are examined first. Cnoidal waves with wave height $H$ varying from $1.0 \mathrm{~m}$ to $4.0 \mathrm{~m}$ and period $T$ from $8.0 \mathrm{~s}$ to $13.0 \mathrm{~s}$ are considered. For these simulations, the sizes of the numerical tank are set as follows: $L=800 \mathrm{~m}, B=260 \mathrm{~m}, d=20 \mathrm{~m}, L_{1}=600 \mathrm{~m}$, $L_{2}=200 \mathrm{~m}, \Delta x=2 \mathrm{~m}, \Delta y=3 \mathrm{~m}$, and $\Delta z=2 \mathrm{~m}$. Figure 3 shows the simulated wave surface elevations along the wave tank for a cnoidal wave with incident height $H=3 \mathrm{~m}$ and period $T=10 \mathrm{~s}$. It is found that the simulated waves can fit the targeted wave very well and the surface elevations are quite uniform and stable. Increasing propagation distance, due to triad nonlinear interactions, the wave crests become more and more sharp and the troughs are flattened, consisting with the shape characteristics of shallow water waves $[25,26]$. The snapshots of the simulation case are illustrated in Figure 4, which shows that the waves are quite uniform along the $y$ direction and the sponge layer works well for the damping of wave energy. The present model also works well for other tests, and the results are not shown here for brevity.

3.2. Wave Pressures on a Perforated Rectangular Caisson. To further investigate the validation of the model, simulations on the interactions between waves and a perforated rectangular caisson are carried out. Then, the computed results are compared with an existing experiment.

The experiment was conducted in a wave flume located in the State Key Laboratory of Coastal and Offshore Engineering, Dalian University of Technology, China. The flume is $56 \mathrm{~m}$ long, $0.7 \mathrm{~m}$ wide, and $1.0 \mathrm{~m}$ deep. The detailed layout of the experiments can be seen in the work of Liu et al. [13]. Here, only schematic diagrams of the perforated rectangular caisson model and the locations of pressure sensors are illustrated (as shown in Figure 5). The model caisson was $0.3 \mathrm{~m}$ long, $0.68 \mathrm{~m}$ wide, and $0.7 \mathrm{~m}$ height. It was made of Plexiglass plates of $1.0 \mathrm{~cm}$ thickness. The water depth $d$ in front of the structure was $0.4 \mathrm{~m}$. The caisson was divided into four uniform boxes named $\mathrm{A}, \mathrm{B}, \mathrm{C}$, and $\mathrm{D}$ by partition walls. For each box, the front plate was perforated by four rectangular holes from a distance $20 \mathrm{~cm}$ above the bottom plate, and the back wall was solid. The length and width of the holes were $0.11 \mathrm{~m}$ and $0.074 \mathrm{~m}$, respectively. As marked in Figure 5, three pressure sensors (1\#, 2\#, and 3\#) were placed on the front walls of the B box and another three sensors (4\#, $5 \#$, and 6\#) were fixed on the back wall of the C.

In the experiment, cnoidal waves with incident wave height $6 \mathrm{~cm}$ and wave period $1.2 \mathrm{~s}$ were generated by the wave paddle. For the simulation, the mesh sizes of the numerical 


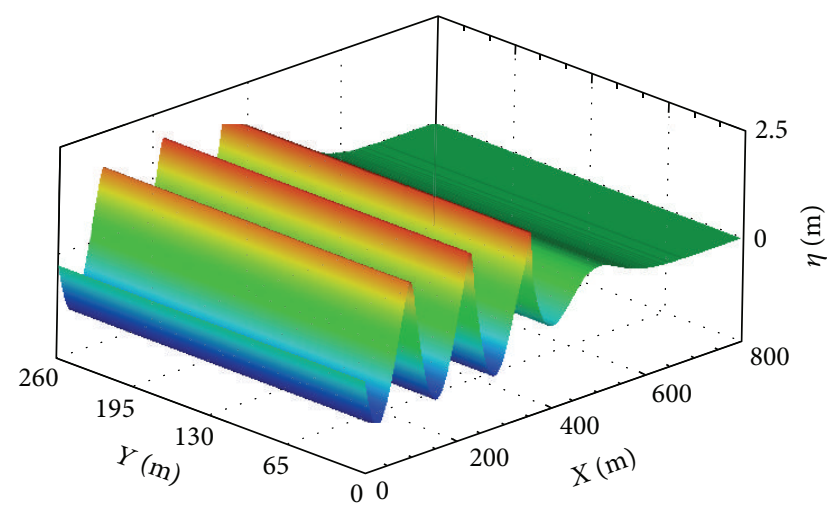

(a) $t=40.0 \mathrm{~s}$

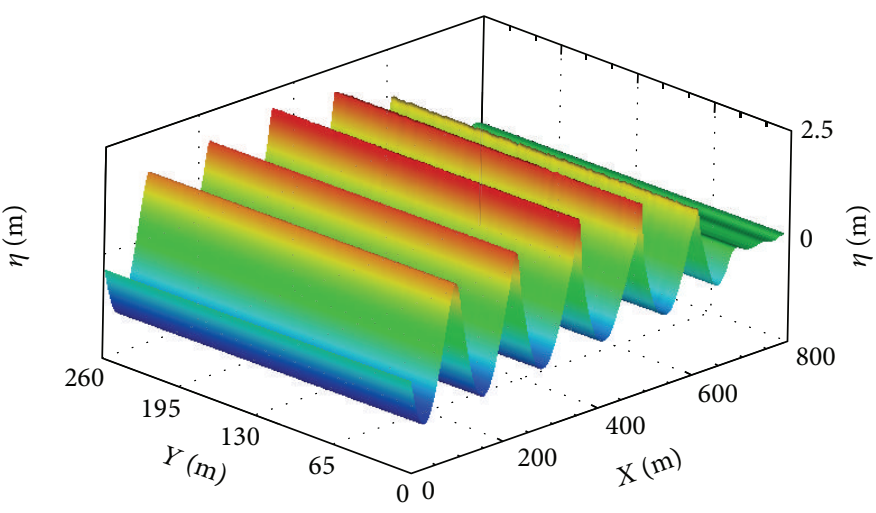

(b) $t=120.0 \mathrm{~s}$

FIGURE 4: Snapshots of the numerical tank for the simulation of waves with $H=3 \mathrm{~m}, T=10 \mathrm{~s}$.

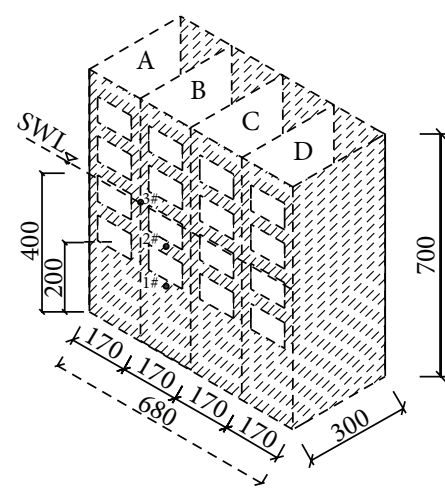

(a)

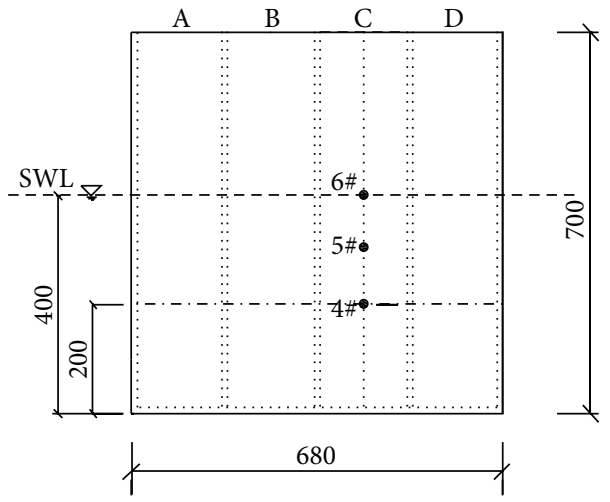

(b)

FIGURE 5: Sketch of the perforated caisson model (unit: $\mathrm{mm}$ ) and the placement of pressure sensors: (a) oblique front view, (b) back view.

tank are set as follows: $\Delta x=3 \mathrm{~cm}, \Delta y=4.05 \mathrm{~cm}$, and $\Delta z=4.25 \mathrm{~cm}$. The comparisons between the simulated and experimental results are shown in Figure 6. It is found that the computed pressure matches well with experimental results under the water surface (sensors 1\#, 2\#, 4\#, and 5\#). For the locations close to the water surface (sensors $3 \#$ and 6\#), the computation slightly overestimates the results at the troughs of the pressure time history. The discrepancy may be mainly due to the complex flow characteristics near the water surface caused by strong interactions between the waves and the structure.

The above discussion indicates that the present threedimensional numerical model can be used to investigate the interactions between waves and coastal structures. In the next section, the model will be used to study the interactions between waves and quasi-ellipse caissons.

\section{Waves Interaction with Perforated Quasi-Ellipse Caissons}

4.1. Description of Quasi-Ellipse Caissons. A quasi-ellipse caisson is made up by two hollow semicylinders which are connected by two rectangular plates to form a chamber [20]. Figure 7 shows a cross section of a quasi-ellipse, $D$ denotes the diameter the semicylinders, and $B$ is the length of the rectangular plates. In this study, the values of $D$ and $B$ are fixed for all simulations: $D=20 \mathrm{~m}$ and $B=12 \mathrm{~m}$. For multiple caissons, $D_{c}$ represents the distance between caissons. In this study, the caissons are perforated by rectangular holes with $3 \mathrm{~m}$ in height and $4 \mathrm{~m}$ in length and the positions of the holes are marked in Figure 8.

As mentioned in the previous section, the computation domain of the model is divided by regular cuboid cells. However, for quasi-ellipse caissons, some cells at the boundaries cannot be fully occupied by the solid boundaries (see Figure 9). To solve this problem, the partial cell method, which is also used to descript the free surface, is adopted. As shown in Figure 9, solid straight lines are used to represent the intersection lines between the caisson boundary and the fluid for simplicity.

4.2. Numerical Results. For the simulations of wave interaction with quasi-ellipse caissons, the sizes of the numerical tank are set as follows: $L=800 \mathrm{~m}, B=260 \mathrm{~m}, d=20 \mathrm{~m}$, $L_{1}=600 \mathrm{~m}, L_{2}=200 \mathrm{~m}, \Delta x=2 \mathrm{~m}, \Delta y=3 \mathrm{~m}$, and $\Delta z=2 \mathrm{~m}$. Figure 10 shows the distribution of surface elevations around the multiple quasi-ellipse caissons in a wave period and the adjacent distance between the caissons $D_{c}$ is set equal to $2 D$ 

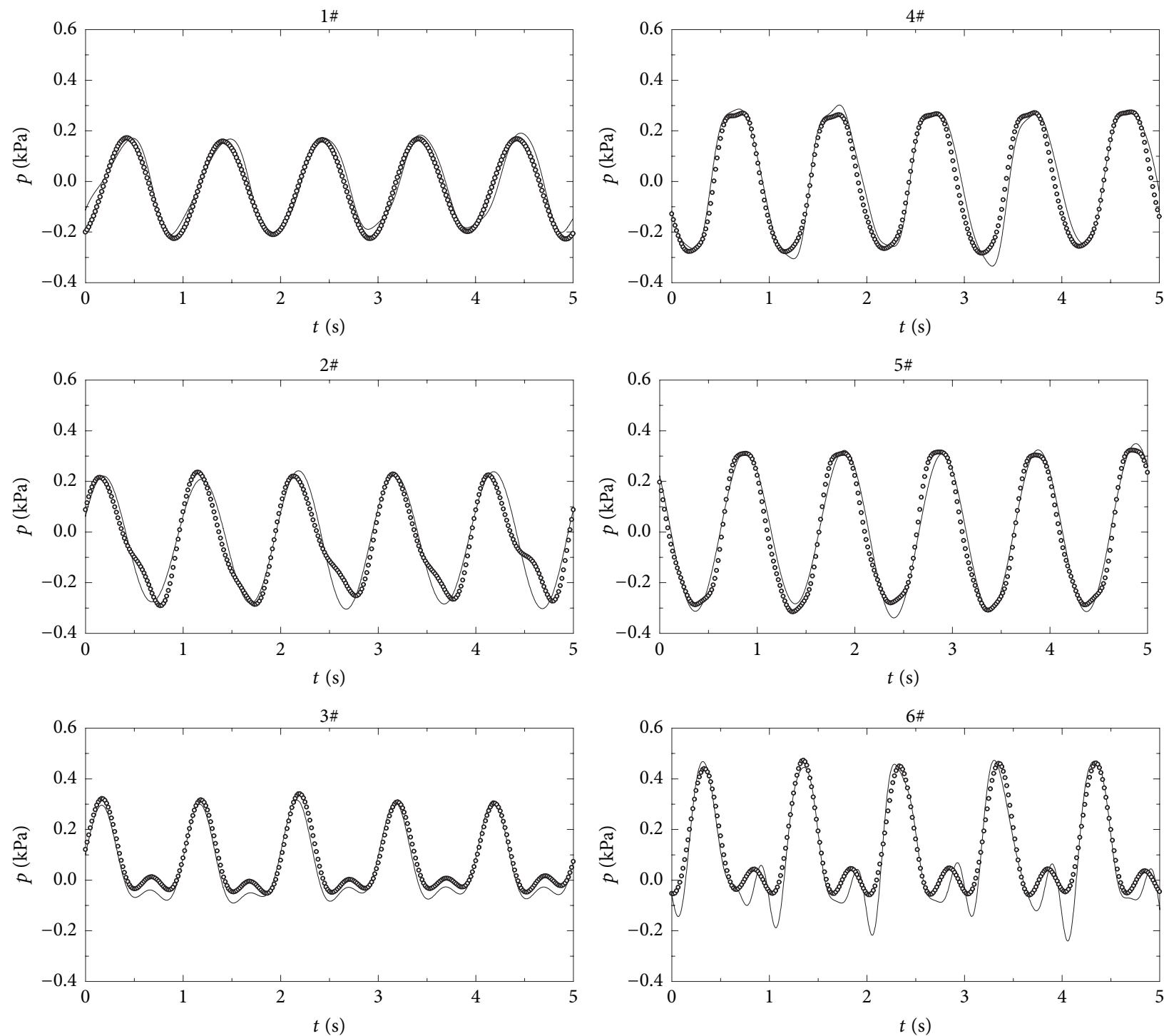

FIGURE 6: Comparisons of the time series of wave pressures on the perforated rectangular caisson: (open circles) experimental results, (solid lines) numerical results.

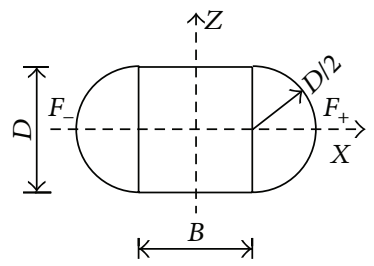

(a)

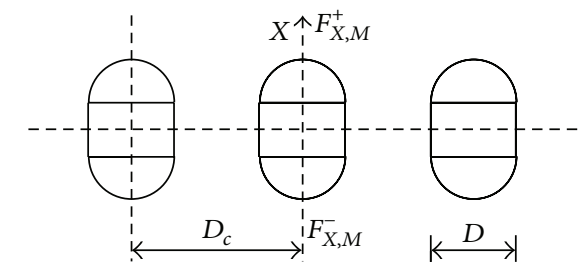

(b)

FIGURE 7: Sketch of a quasi-ellipse caisson (a) and multiple quasi-ellipse caissons (b).

(40 m). For this simulation, the height of the incident cnoidal wave is $3 \mathrm{~m}$ with a period of $10 \mathrm{~s}$. As wave crest approaches the front faces of the caissons, the runup of waves is very high and partially caused by significant reflection of the caissons. The difference between the front and rear faces in this situation is pronounced, suggesting that the wave forces on the caissons are very large. It is noticed that the surface elevations between the caissons are also remarkable. The results for the perforated caissons are shown in Figure 11. The surface elevations close to the caissons are reduced compared to that without perforation, indicating that the perforation can reduce the wave runup/rundown on the caissons. The surface elevations between the caissons are also significantly weakened. 

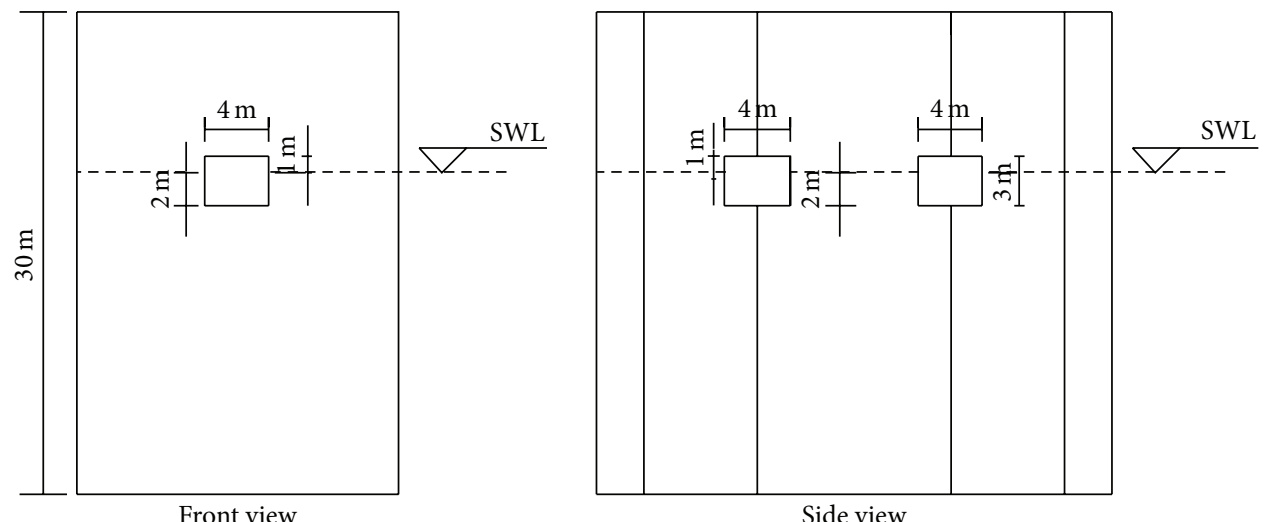

FIGURE 8: Sketch of a perforated quasi-ellipse caisson.

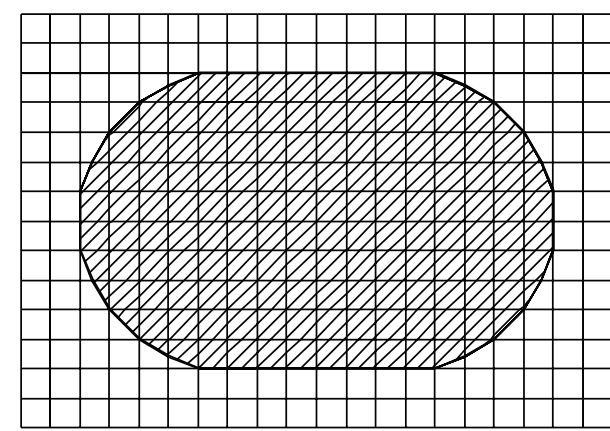

(a) Solid quasi-ellipse caisson

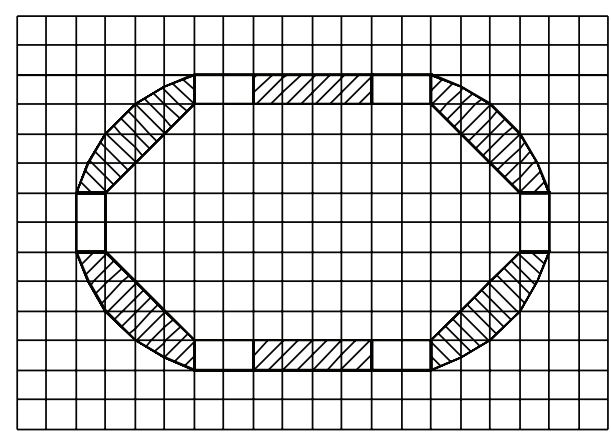

(b) Perforated quasi-ellipse caisson

FIGURE 9: Sketch of the mesh division of a cross section for the numerical model.

The perforation on caissons can enhance the water exchange, wave energy is partially dissipated by the perforated wall and some wave energy is transferred to the fluid inside the chamber of the caissons (see Figure 12), and hence the wave reflection and runup are reduced. As the wave troughs approach the middle of the caissons (Figure 12(a)), the difference of water levels between inside and outside of the chambers is pronounced, which causes the water flow to the outside. Therefore, the wave height in the middle of the caisson is reduced. For the time when the wave crests are close to this region, the wave flow direction is reversed (Figure 12(c)), and the wave height outside the chambers is decreased. The intensive water exchange between inside and outside of the chambers suggests that wave energy is dissipated significantly.

The previous discussion suggests the perforation can significantly reduce the wave force of the caissons. In this section, the wave forces and the influence factor will be investigated for multiple caissons. To achieve these targets, cnoidal waves with different incident height and period are generated and the interactions between the waves and a caisson without peroration are simulated first and then the multiple placed caissons. Following the definition of wave force used for an isolated square structure [21], the nondimensional wave force on the single placed caisson can be written as

$$
F_{x, S}=\frac{F_{x}}{\rho g(B+D) d^{2}[\tanh (k d) / k d]},
$$

where $k$ is the wave number of the incident wave and $F_{x}$ is the maximum wave force in the $x$ direction and can be obtained by integrating the surface pressure on the structure.

The wave forces on the single placed caisson are shown in Figure 13. As expected, higher incident waves $(H / d=$ 0.15) can produce larger wave forces. With decreasing of wave period (i.e., $k$ is increased), wave force on the caisson is increased.

For convenient illustration and comparison, the wave forces on a single placed caisson without perforation are used as benchmark. Then, a nondimensional force, which can reflect the influence of multiple placement, is defined as

$$
R_{x}=\frac{\left|F_{x, M}\right|}{\left|F_{x, S}\right|}
$$

where $F_{x, M}$ is maximum force in $x$ direction for the central one of the caisson group (as illustrated in Figure 7).

The nondimensional forces $R_{x}$ on the middle caisson without perforation are shown in Figure 14. It is found that the values of $R_{x}$ are larger than 1 for all the simulated cases, indicating that the presence of adjacent caissons can increase the wave force. With decreasing incident wave period (i.e., increasing $k D$ ), $R_{x}$ decreases. Additionally, $R_{x}$ for the cases in the condition with $D_{c} / D=2$ is significantly larger than those cases with larger transverse distance $D_{c}$. But the $R_{x}$ differences between the cases in the conditions $D_{c} / D=3$ and $D_{c} / D=4$ are much smaller, especially for the cases with $k D>1.0$. By increasing incident wave nonlinearity, 


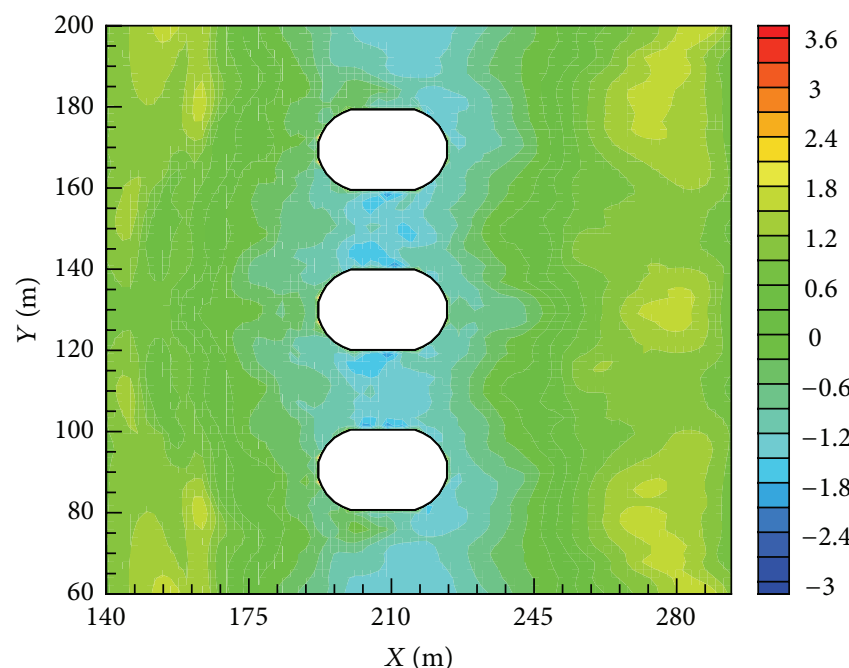

(a) $t=45 T$

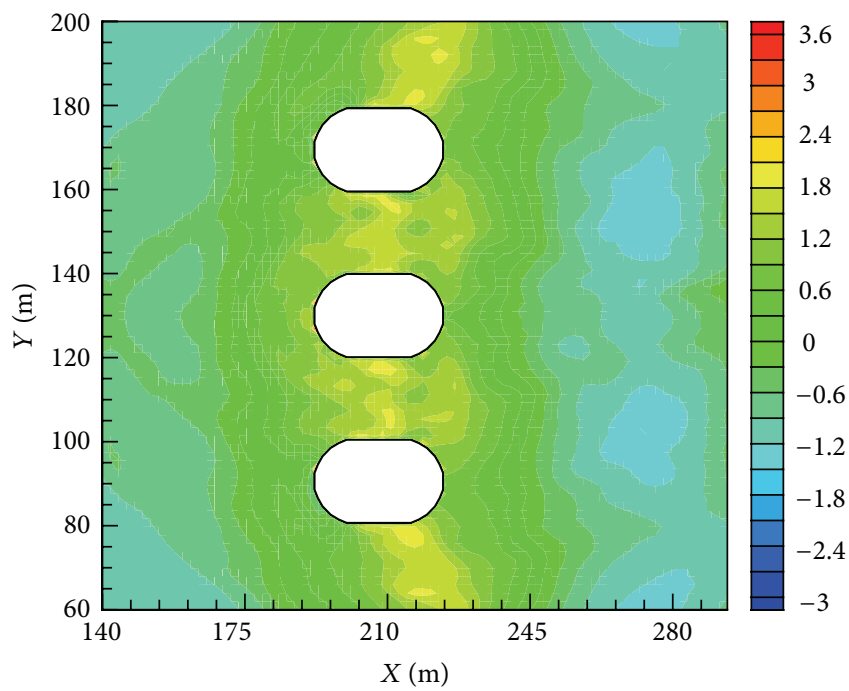

(c) $t=(45+0.5) T$

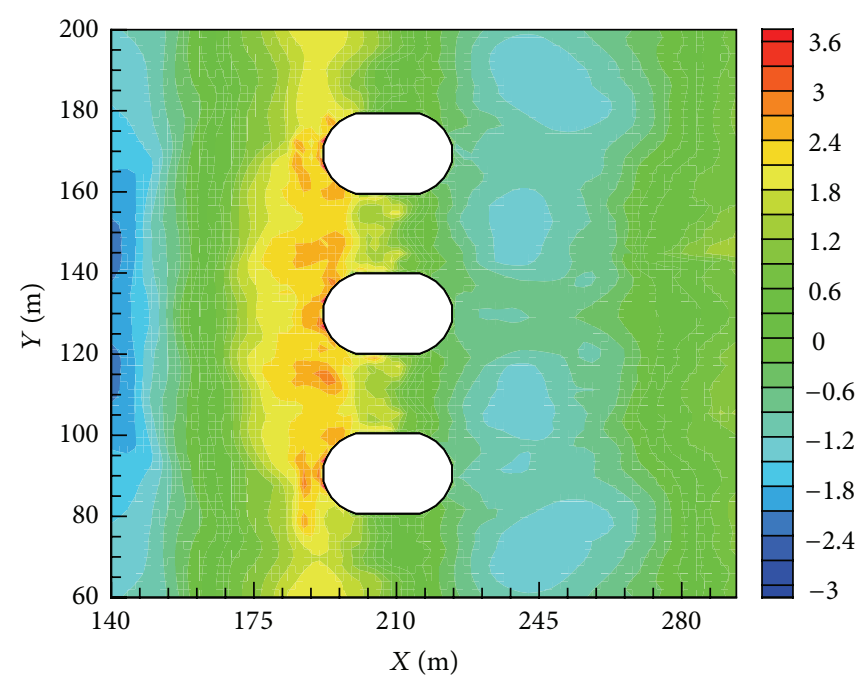

(b) $t=(45+0.25) T$

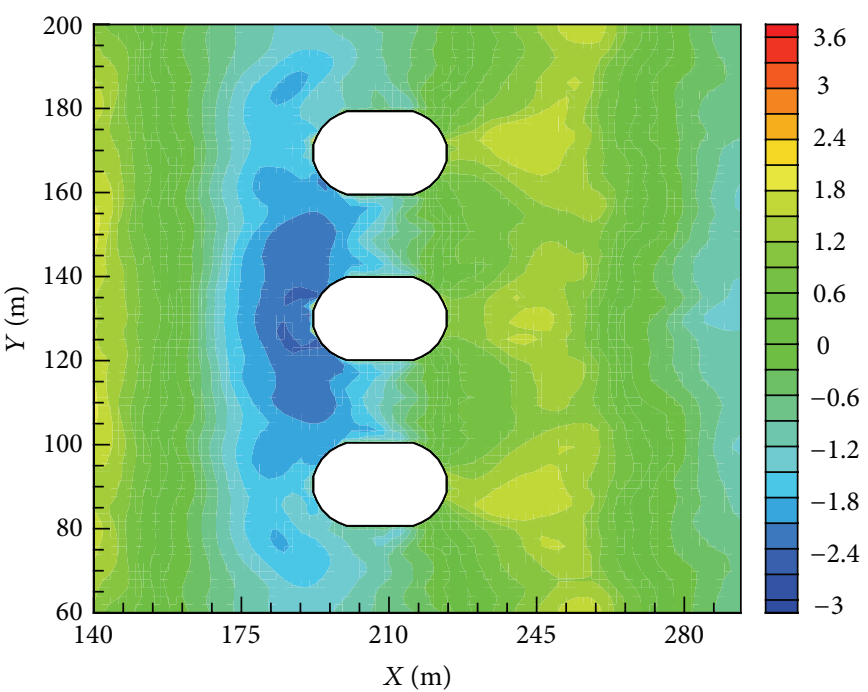

(d) $t=(45+0.75) T$

FIGURE 10: Contours of water surface elevations around multiple impermeable quasi-ellipse caissons in a wave period $(T=10 \mathrm{~s}, H=3.0 \mathrm{~m})$, unit (m).

$R_{x}$ can also be enhanced but the increment is limited. For the tests with perforation, the influence of incident wave period and adjacent distance on the forces has a similar trend (see Figure 15).

To directly reveal the influence of the perforation, the $R_{x}$ difference between the impermeable caisson and the perforated one is defined as

$$
Q_{x}=\left|R_{x, s}-R_{x, p}\right| \text {, }
$$

where $R_{x, s}$ is the relative wave for the caisson without perforation and $R_{x, p}$ is for the perforated one. Figure 16 demonstrates the variations of $Q_{x}$ for all the simulated cases. For tests with the smaller incident wave height $(H / d=0.05)$, the reduction of wave forces by the perforation increases with the decrease of wave period. The distance between the caissons $D_{c}$ also has influence on the reduction wave forces.
But if the adjacent distance is larger enough, the influence is limited for smaller incident waves. For incident waves with higher nonlinearity (i.e., $H / d=0.15$ ), the effect of perforation appears smaller than the cases with the smaller incident waves. The wave period effect for the conditions with $D_{c} / D=3.0$ and 4.0 follows the trend of the cases with the smaller incident height. However, the tendency for the condition $D_{c} / D=2.0$ is much complex. When $k D<1.0$, the perforation works better than those conditions with larger transverse distances.

\section{Conclusions}

A three-dimensional numerical wave flume was established using the continuity equation and the Navier-Stokes equations. The VOF method was adopted to capture the free surfaces. The ability of generation of cnoidal waves and its 


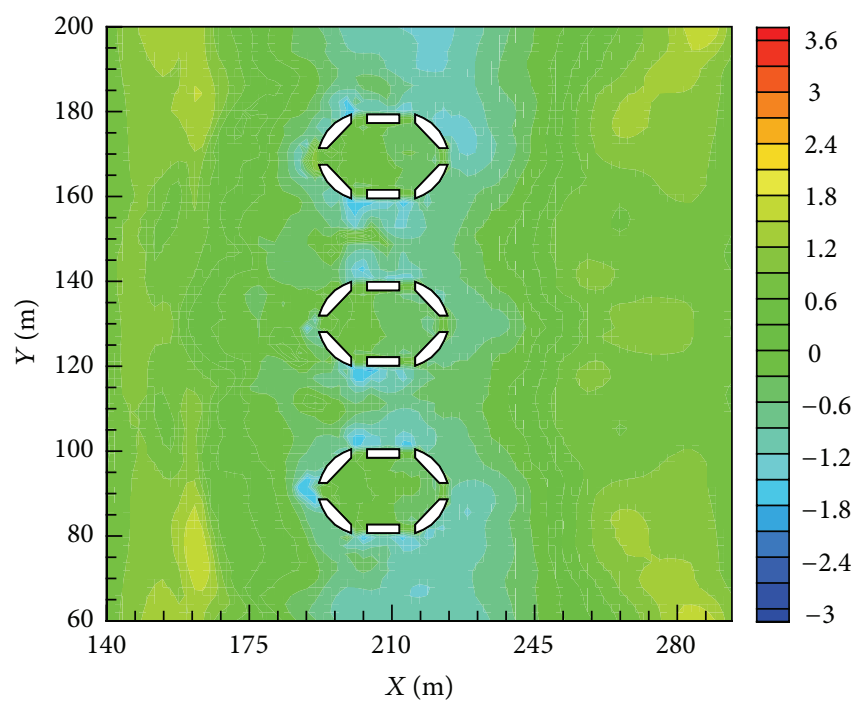

(a) $t=45 \mathrm{~T}$

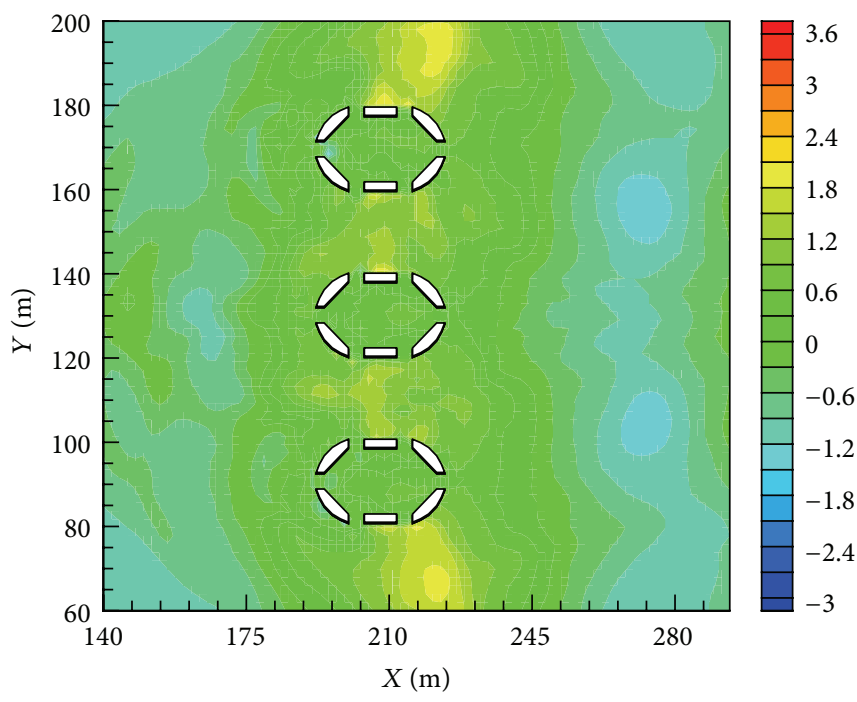

(c) $t=(45+0.5) T$

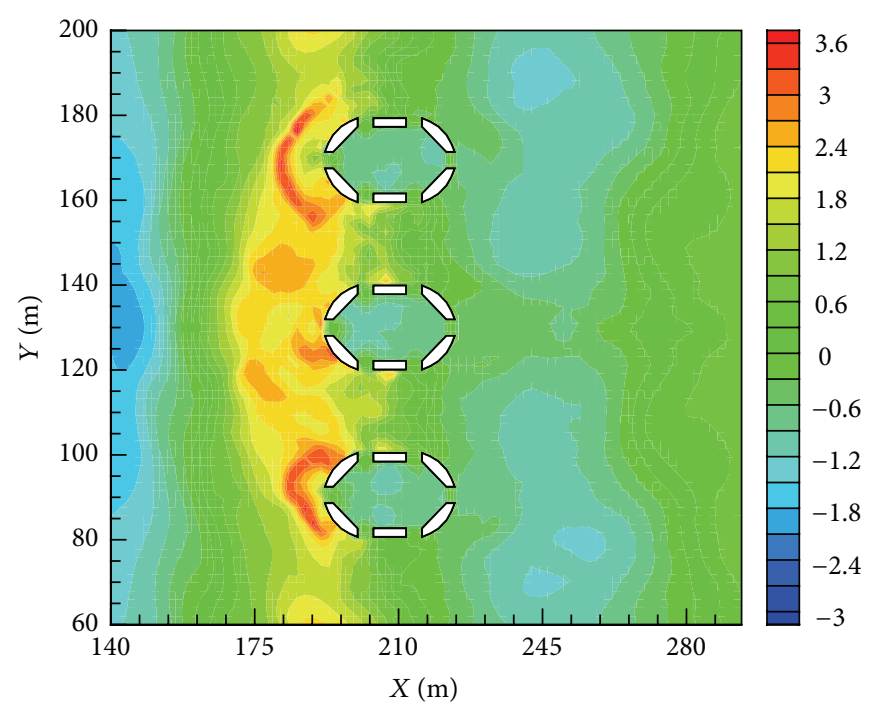

(b) $t=(45+0.25) T$

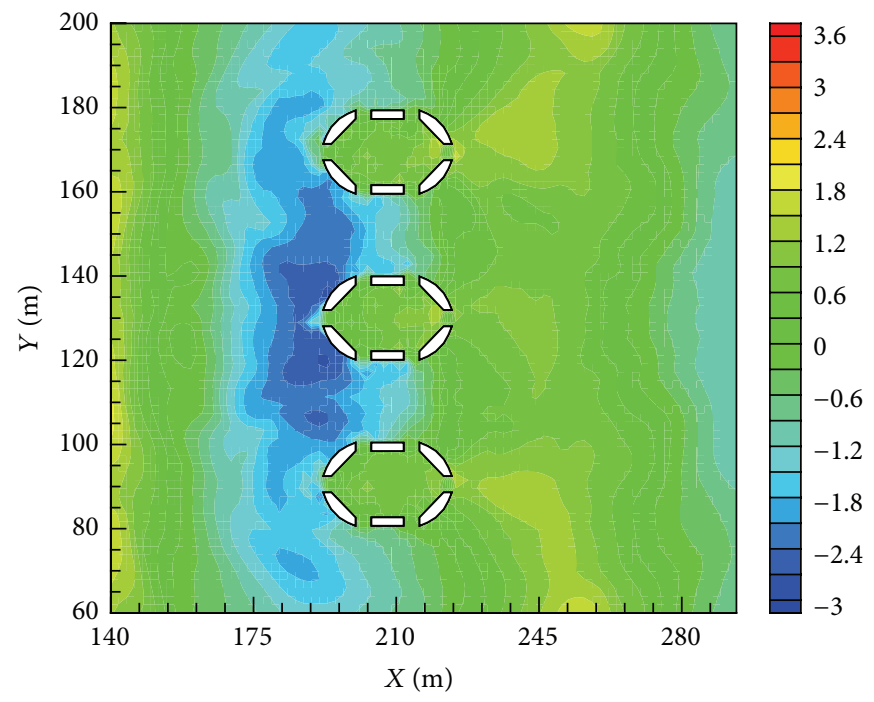

(d) $t=(45+0.75) T$

FIGURE 11: Contours of water surface elevations around multiple perforated quasi-ellipse caissons in a wave period $(T=10 \mathrm{~s}, H=3.0 \mathrm{~m})$, unit $(\mathrm{m})$.

interaction with a perforated rectangle caisson were verified using the existing experimental data. Then, the present model was used to investigate interactions between cnoidal waves with varying incident height and period and multiple perforated quasi-ellipse caissons. The influence of the perforation on the wave field and the velocity flow around the caissons was examined. The numerical results demonstrate that the wave runup/rundown on the caissons was reduced significantly by perforation and hence the wave forces are also decreased. The reduction of wave runup/rundown is mainly due to the extensive water exchange inside and outside the caisson chamber. It is also found that the effect of the presence of adjacent caissons on wave forces decreases with decreasing incident wave period for both multiple placed caissons with and without perforation. The wave forces for closer transverse adjacent distance are larger than those conditions with a farther distance, but when relative adjacent distance $D_{c} / D\left(D_{c}\right.$ is the transverse distance and $D$ is the width of the quasi-ellipse caisson) is larger than 3 , the effect of adjacent distance is limited. Additionally, the effect of the perforation increases with the reduction of incident wave period. The performance of the perforation is better when incident wave height is small, suggesting that wave nonlinearity also plays an important role in the process of interaction.

\section{Conflict of Interests}

The authors declare that there is no conflict of interests regarding the publication of this paper. 


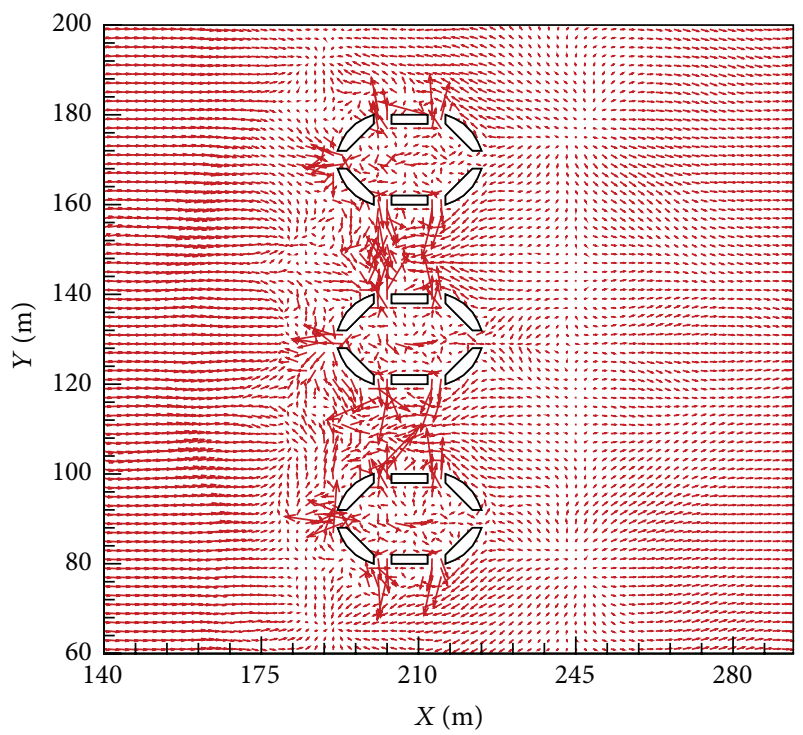

(a) $t=45 T$

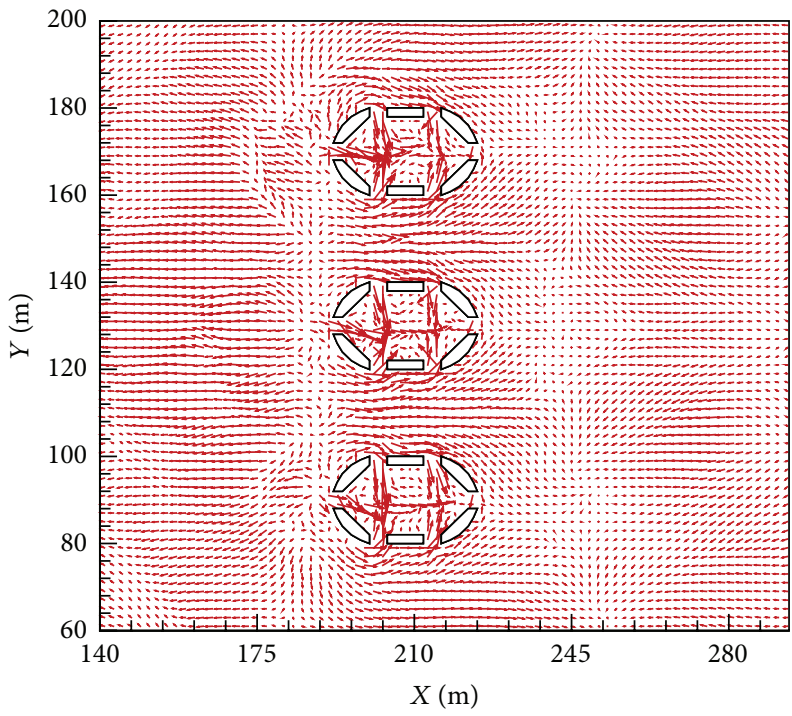

(c) $t=(45+0.5) T$

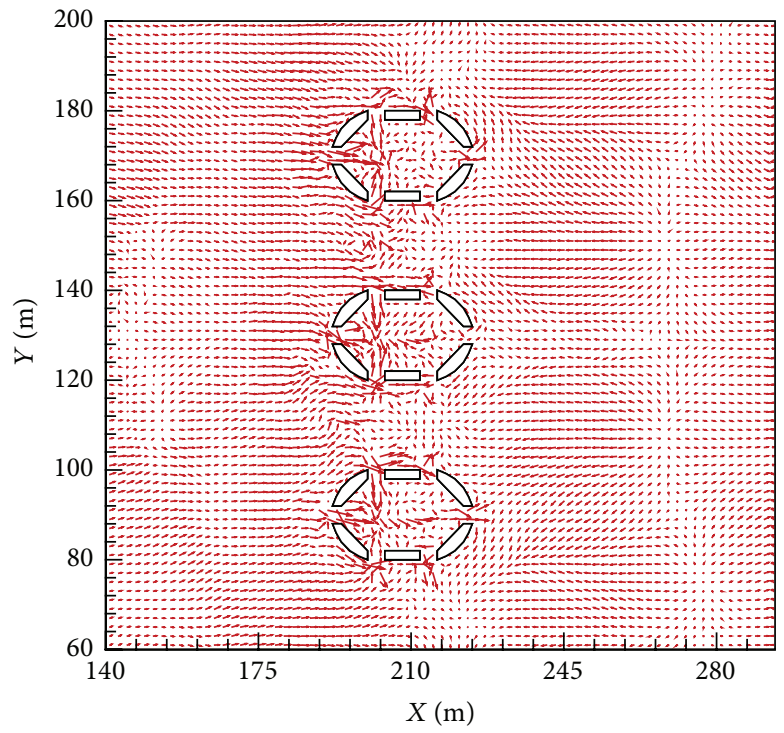

(b) $t=(45+0.25) T$

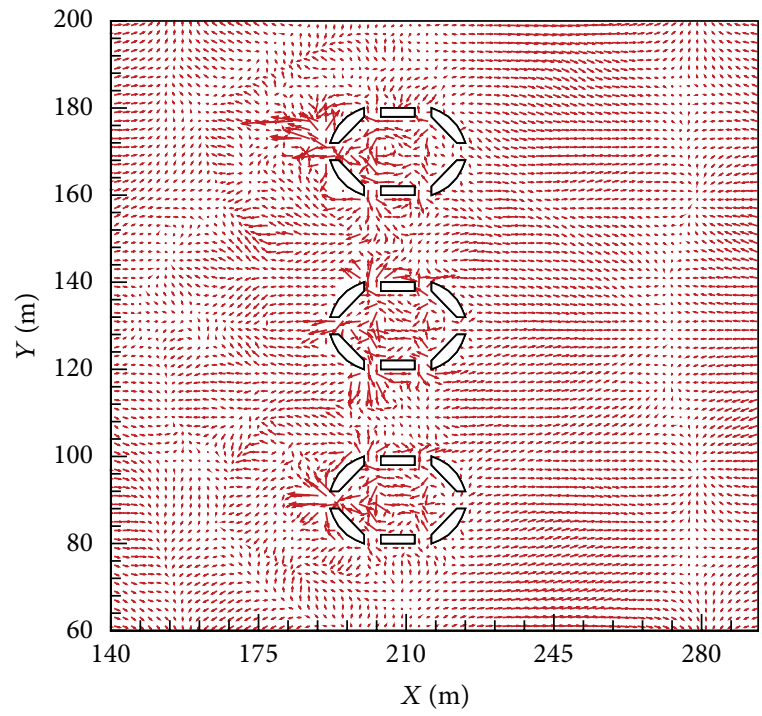

(d) $t=(45+0.75) T$

FIGURE 12: The flow vector fields corresponding to the wave surface elevations of Figure 11.

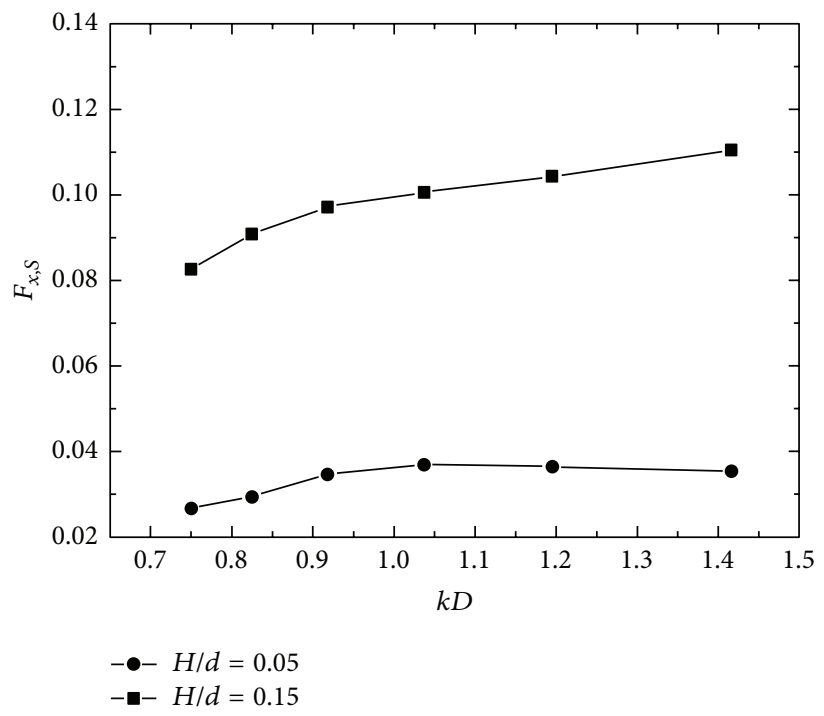

FIGURE 13: Variations of wave forces on an isolated caisson without perforation. 

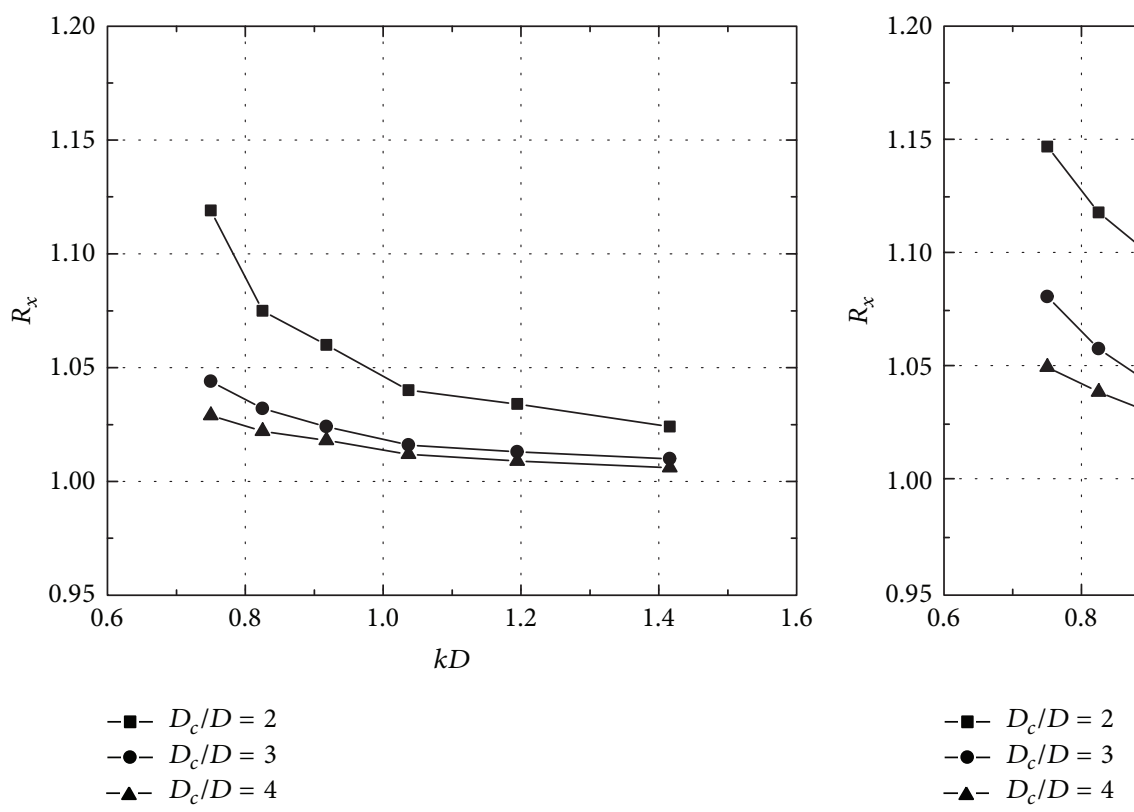

(a)

(b)

FIGURE 14: Influence of transverse distance $L$ on the nondimensional wave forces $R_{x}$ of the caisson without perforation: (a) cases with $H / d=$ 0.05 , (b) cases with $H / d=0.15$.
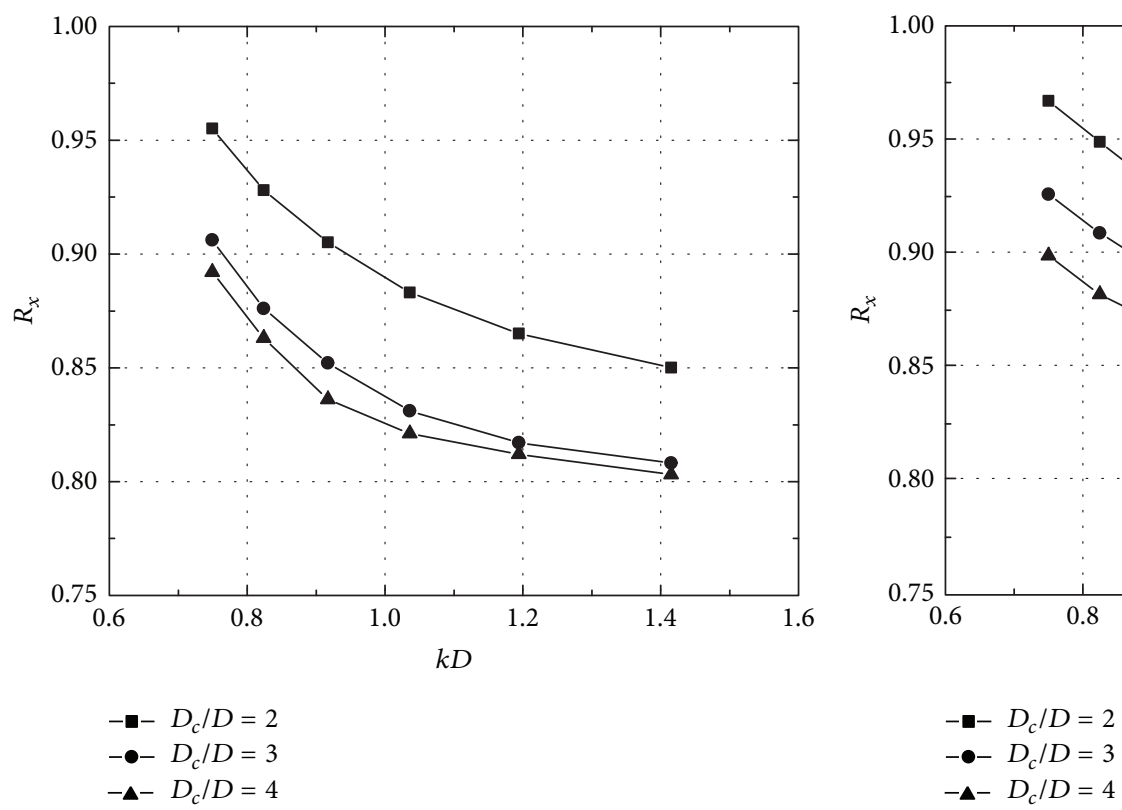

(a)

(b)

FIGURE 15: Influence of transverse distance $L$ on the nondimensional wave forces $R_{x}$ of the caisson without perforation: (a) cases with $H / d=$ 0.05 , (b) cases with $H / d=0.15$. 


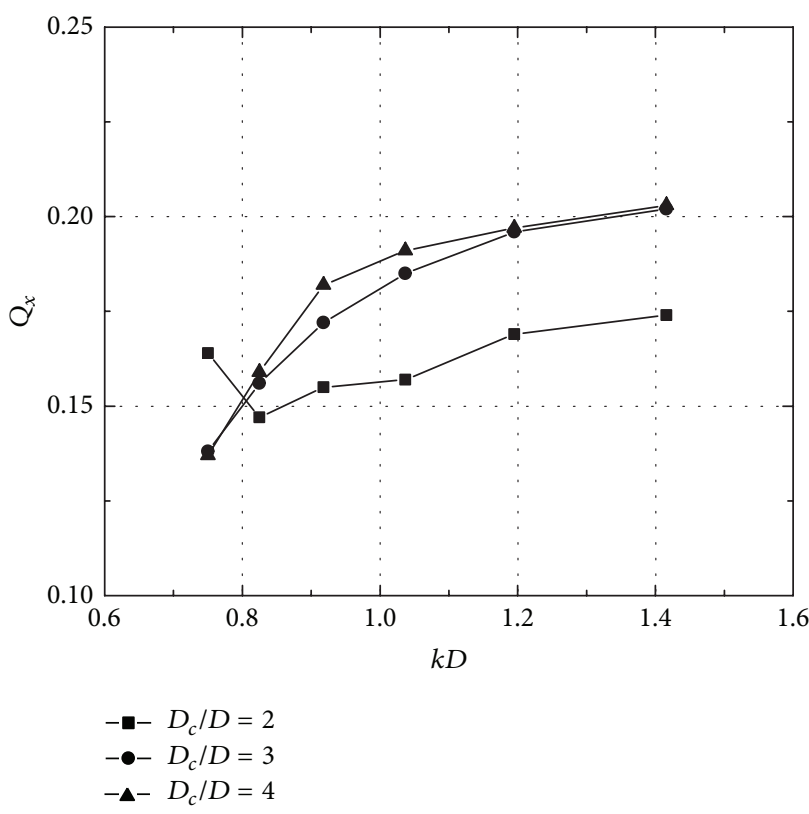

(a)

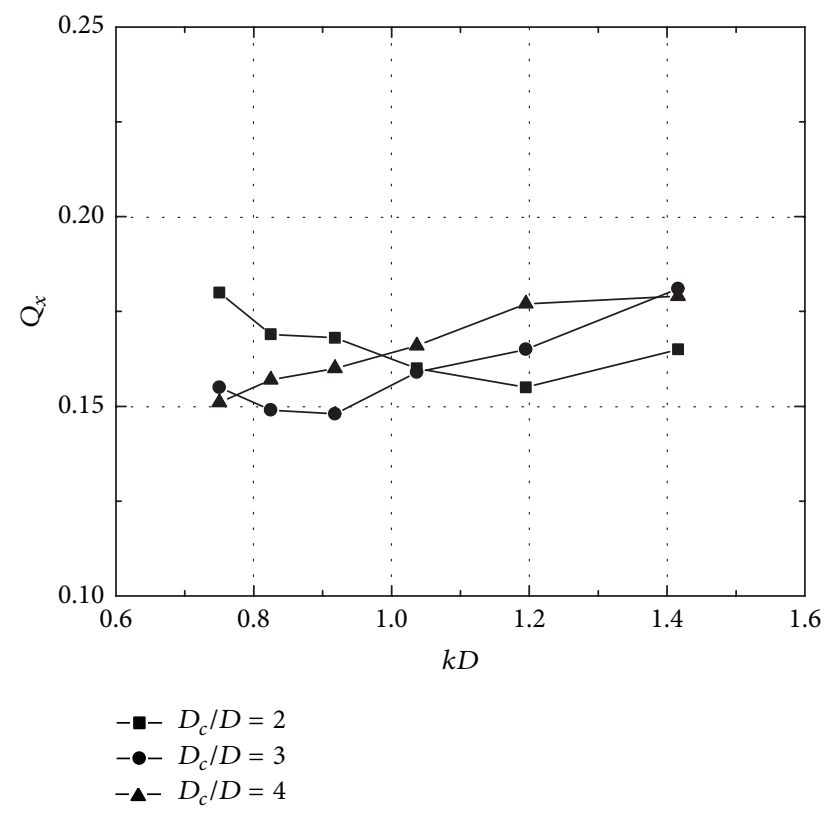

(b)

FIGURE 16: Variations of $Q_{x}$ with respect to incident wave period for cases in conditions with different transverse distance $L$ : (a) cases with $H / d=0.05$, (b) cases with $H / d=0.15$.

\section{Acknowledgments}

This research is supported financially by the National Natural Science Foundation (Grant nos. 51422901 and 51221961) and A Foundation for the Author of National Excellent Doctoral Dissertation of PR China (Grant no. 201347).

\section{References}

[1] G. E. Jarlan, "A perforated vertical wall breakwater," The Dock and Harbour Authority, vol. 41, no. 486, pp. 394-398, 1961.

[2] Z. Huang, Y. Li, and Y. Liu, "Hydraulic performance and wave loadings of perforated/slotted coastal structures: a review," Ocean Engineering, vol. 38, no. 10, pp. 1031-1053, 2011.

[3] M. K. M. Darwiche, A. N. Williams, and K.-H. Wang, "Wave interaction with semiporous cylindrical breakwater," Journal of Waterway, Port, Coastal, and Ocean Engineering, vol. 120, no. 4, pp. 382-403, 1994.

[4] T. L. Yip and A. T. Chwang, "Perforated wall breakwater with internal horizontal plate," Journal of Engineering Mechanics, vol. 126, no. 5, pp. 533-538, 2000.

[5] K. D. Suh, J. C. Choi, B. H. Kim, W. S. Park, and K. S. Lee, "Reflection of irregular waves from perforated-wall caisson breakwaters," Coastal Engineering, vol. 44, no. 2, pp. 141-151, 2001.

[6] Y. C. Li, H. J. Liu, B. Teng, and D. P. Sun, "Reflection of oblique incident waves by breakwaters with partially perforated wall," China Ocean Engineering, vol. 16, no. 3, pp. 329-342, 2002.

[7] Y. C. Li, G. H. Dong, H. J. Liu, and D. P. Sun, "The reflection of oblique incident waves by breakwaters with double-layered perforated wall," Coastal Engineering, vol. 50, no. 1-2, pp. 47-60, 2003.
[8] Y. Liu, Y.-C. Li, and B. Teng, "Wave interaction with a perforated wall breakwater with a submerged horizontal porous plate," Ocean Engineering, vol. 34, no. 17-18, pp. 2364-2373, 2007.

[9] Y. Liu, Y.-C. Li, and B. Teng, "The reflection of oblique waves by an infinite number of partially perforated caissons," Ocean Engineering, vol. 34, no. 14-15, pp. 1965-1976, 2007.

[10] K. Sankarbabu, S. A. Sannasiraj, and V. Sundar, "Hydrodynamic performance of a dual cylindrical caisson breakwater," Coastal Engineering, vol. 55, no. 6, pp. 431-446, 2008.

[11] S. Neelamani, G. Koether, H. Schüttrumpf, M. Muttray, and H. Oumeraci, "Wave forces on, and water-surface fluctuations around a vertical cylinder encircled by a perforated square caisson," Ocean Engineering, vol. 27, no. 7, pp. 775-800, 2000.

[12] K. Vijayalakshmi, S. Neelamani, R. Sundaravadivelu, and K. Murali, "Wave runup on a concentric twin perforated circular cylinder," Ocean Engineering, vol. 34, no. 2, pp. 327-336, 2007.

[13] Y. Liu, Y. Li, B. Teng, J. Jiang, and B. Ma, “Total horizontal and vertical forces of irregular waves on partially perforated caisson breakwaters," Coastal Engineering, vol. 55, no. 6, pp. 537-552, 2008.

[14] J.-I. Lee and S. Shin, "Experimental study on the wave reflection of partially perforated wall caissons with single and double chambers," Ocean Engineering, vol. 91, pp. 1-10, 2014.

[15] J.-I. Lee, Y.-T. Kim, and S. Shin, "Experimental studies on wave interactions of partially perforated wall under obliquely incident waves," The Scientific World Journal, vol. 2014, Article ID 954174, 14 pages, 2014.

[16] X. F. Chen, Y. C. Li, Y. X. Wang, G. H. Dong, and X. Bai, "Numerical simulation of wave interaction with perforated caisson breakwaters," China Ocean Engineering, vol. 17, no. 1, pp. 33-43, 2003.

[17] J. Liu, G. Lin, and J. Li, "Short-crested waves interaction with a concentric cylindrical structure with double-layered perforated walls," Ocean Engineering, vol. 40, pp. 76-90, 2012. 
[18] J. Liu and G. Lin, "Numerical modelling of wave interaction with a concentric cylindrical system with an arc-shaped porous outer cylinder," European Journal of Mechanics-B/Fluids, vol. 37, pp. 59-71, 2013.

[19] F. Aristodemo, D. D. Meringolo, P. Groenenboom, A. Lo Schiavo, P. Veltri, and M. Veltri, "Assessment of dynamic pressures at vertical and perforated breakwaters through diffusive SPH schemes," Mathematical Problems in Engineering, vol. 2015, Article ID 305028, 10 pages, 2015.

[20] J. Bai and J. Hu, "Research on and design of new structure of elliptical caissoned pier," Port and Waterway Engineering, vol. 11, pp. 25-30, 2006 (Chinese).

[21] Y. Wang, X. Ren, and G. Wang, "Numerical simulation of nonlinear wave force on a quasi-ellipse caisson," Journal of Marine Science and Application, vol. 10, no. 3, pp. 265-271, 2011.

[22] C. W. Hirt and B. D. Nichols, "Volume of fluid (VOF) method for the dynamics of free boundaries," Journal of Computational Physics, vol. 39, no. 1, pp. 201-225, 1981.

[23] Y. Wang and T. Su, "Numerical simulation of liquid sloshing in cylindrical containers," Acta Aerodynamica Sinica, vol. 9, no. 1, pp. 112-119, 1991 (Chinese).

[24] Y. Wang, J. Zang, and D. Qiu, "Numerical model of cnoidal wave flume," China Ocean Engineering, vol. 13, no. 4, pp. 391398, 1999.

[25] S. Elgar and R. T. Guza, "Observations of bispectral of shoaling surface gravity waves," Journal of Fluid Mechanics, vol. 161, pp. 425-448, 1985.

[26] G. Dong, Y. Ma, M. Perlin, X. Ma, B. Yu, and J. Xu, "Experimental study of wave-wave nonlinear interactions using the wavelet-based bicoherence," Coastal Engineering, vol. 55, no. 9, pp. 741-752, 2008. 


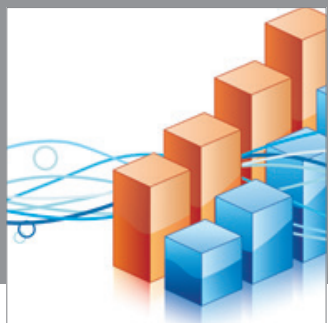

Advances in

Operations Research

mansans

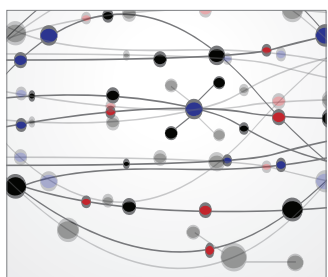

The Scientific World Journal
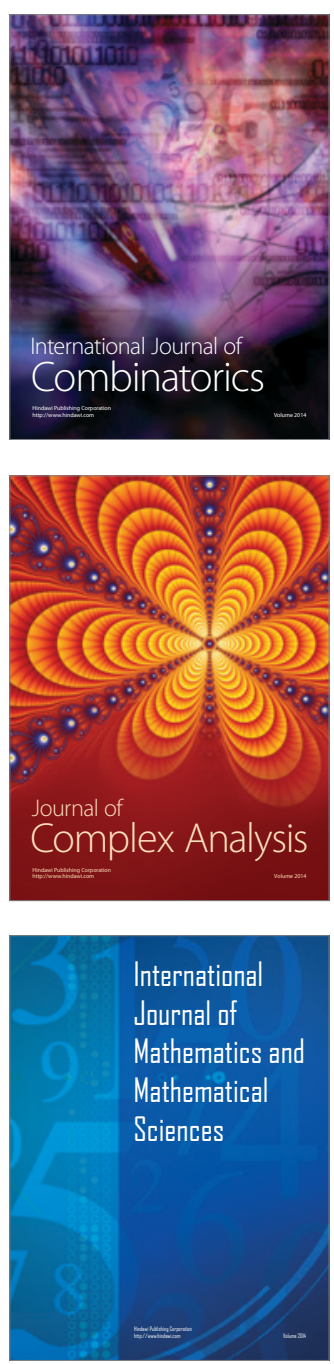
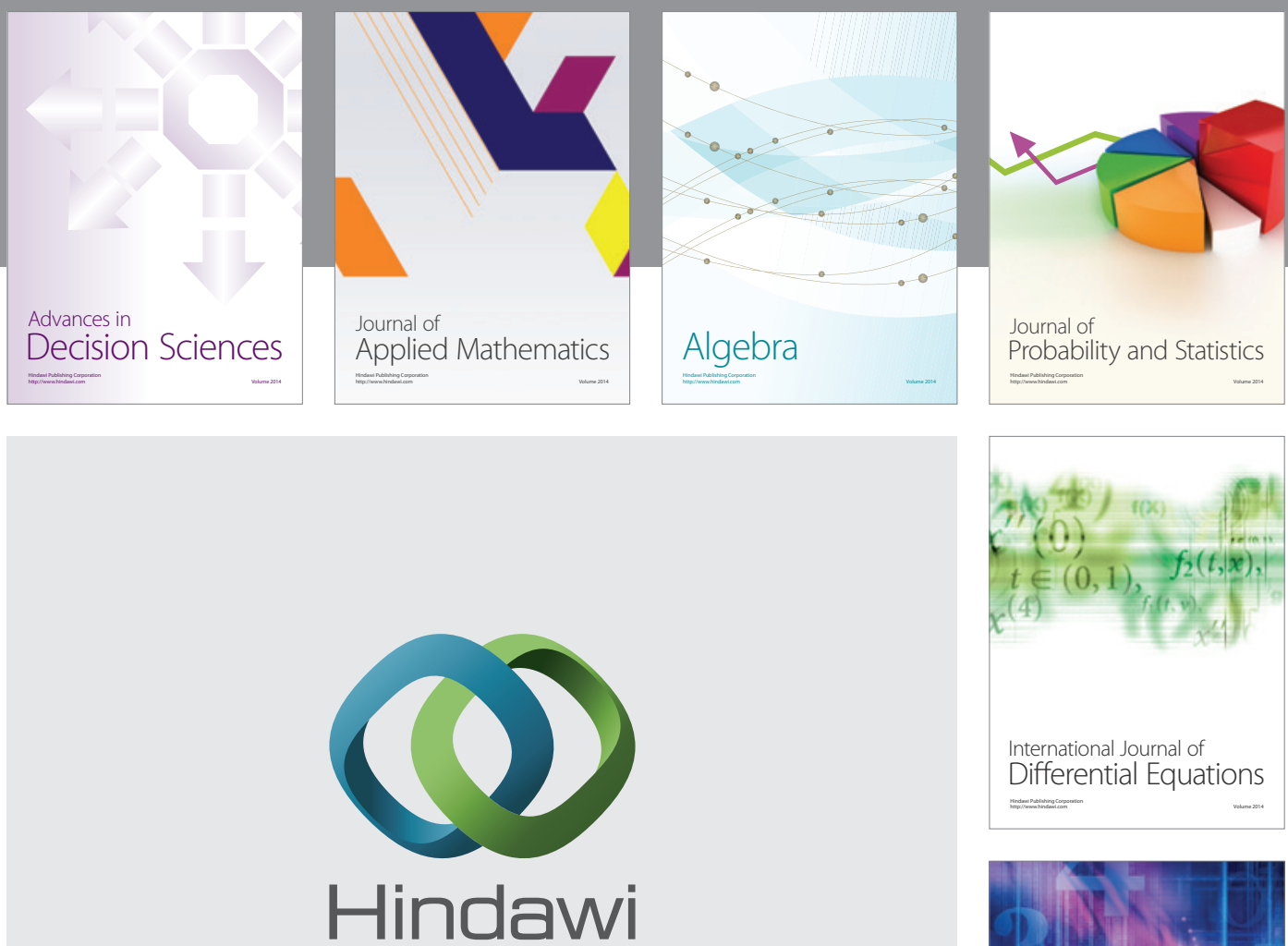

Submit your manuscripts at http://www.hindawi.com
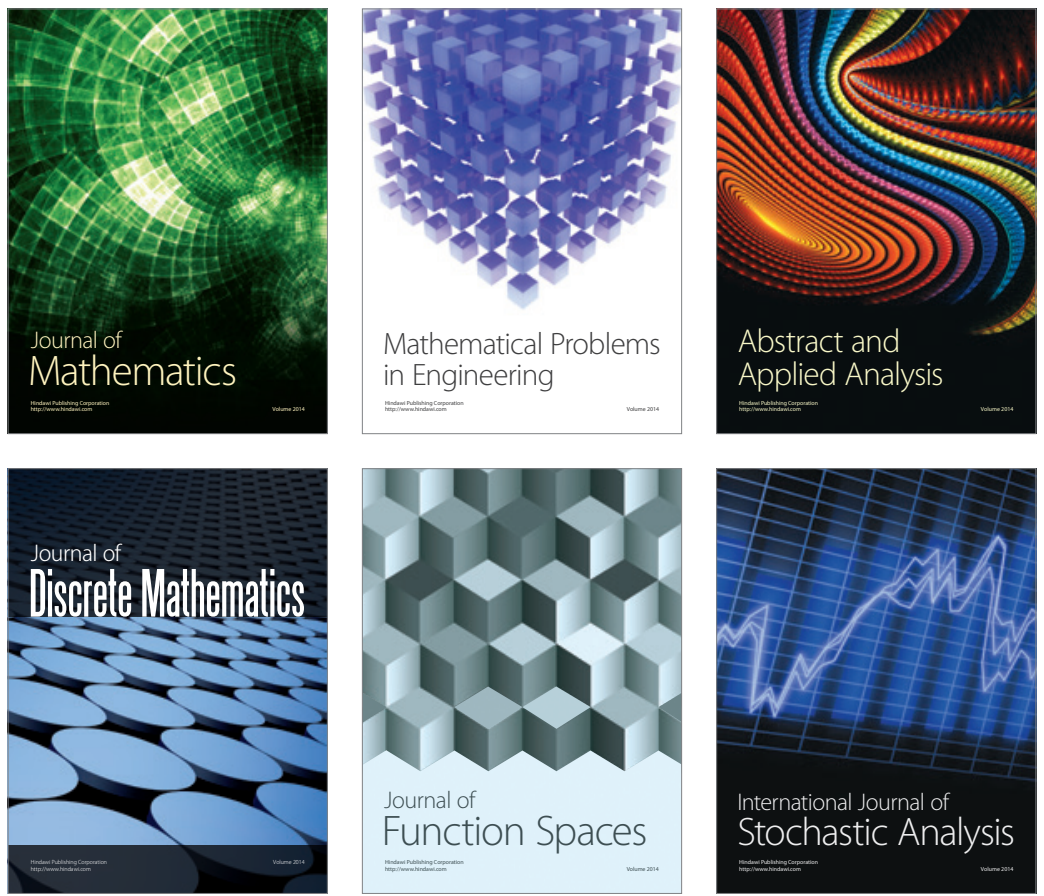

Journal of

Function Spaces

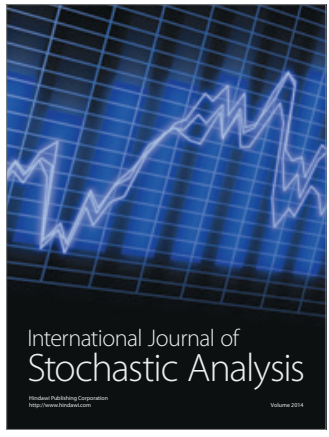

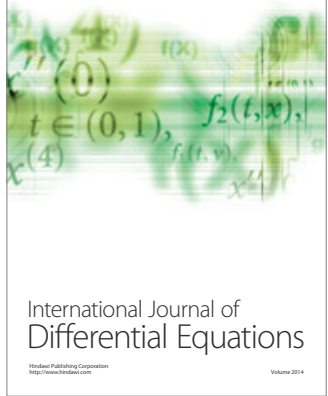
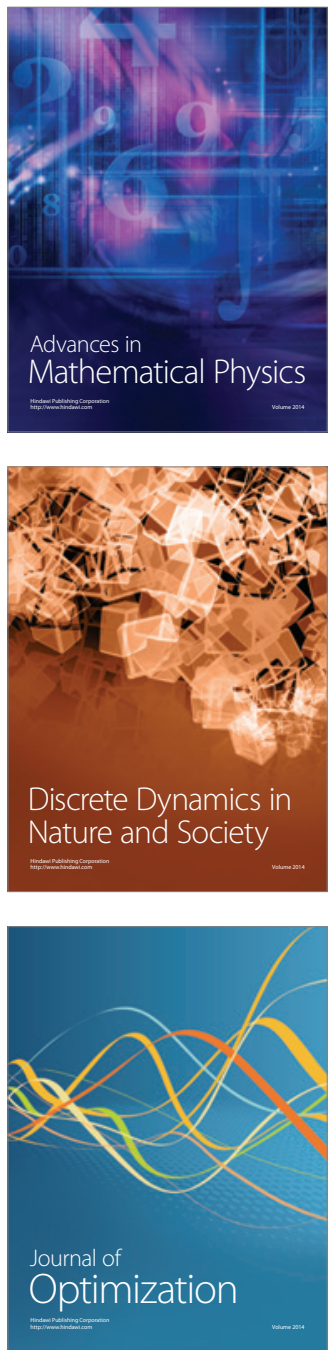